\title{
The Determiners of Behavior at a Choice Point
}

\section{Edward Chace Tolman}

\author{
University of California
}

\section{$\mathbf{T}_{\mathrm{s}}$}

cuss is the very straightforward and specific one of way they do, at a given choice-point in a given maze at a given stage of learning."

The first item in the answer is fairly obvious. They turn the way they do because they have on the preceding trials met this same choicepoint together with such and such further objects or situations, down the one path and down the other, for such and such a number of preceding trials. Let me, however, analyze this further, with the aid of a couple of diagrams. First, consider a diagram of a single choice point (Figure 1).

In this figure the point of choice itself is designated as $O_{c}$; the complex of stimulus-objects met going down the left alley, as $O_{L}$, that met going down the right alley, as $O_{R}$; the goal at the left, as $O_{G L}$; and that at the right, as $O_{G R}$. The behavior of turning to the left is represented by the arrow $B_{L}$; and that of turning to the right, by the arrow $B_{R}$. And

Presidential address delivered before the American Psychological Association, Minneapolis, September 3, 1937. 


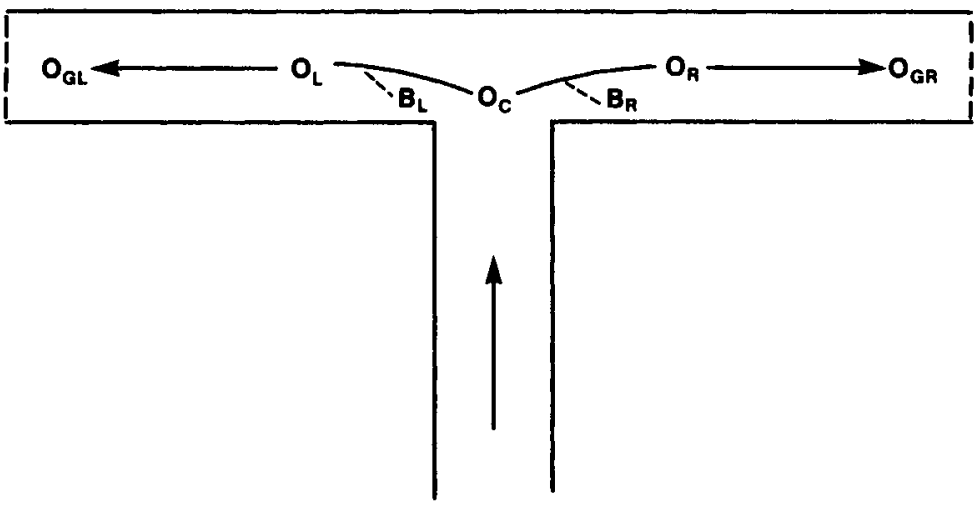

Figure 1.

the point I am now making is that the relative strength of the tendency to turn, say, left (rather than right) will be, first of all, a result not only of the present presentation of $O_{C}$ but also of all the previous presentations of it together with the $O_{L}, O_{G L}, O_{R}$, and $O_{G R}$ consequences of having behaved by $B_{L}$ and $B_{R}$ on all these preceding occasions. In short, I would schematize this feature of the causal determination of the left-turning tendency by the diagram shown in Figure 2.

The expression $B_{L} /\left(B_{L}+B_{R}\right)$ at the right-hand side of Figure 2 is the "dependent variable" (we may call it the behavior-ratio). It is the percentage tendency at any given stage of learning for the group as a whole to turn left. And the hieroglyphic at the left-hand side of this figure is the "independent variable" which determines this behaviorratio. This hieroglyphic is to be read as meaning: the sum of all the preceding occasions in which $O_{C}$ has, by virtue of $B_{L}$, been followed by $O_{L}$ and $O_{G L}$ and by virtue of $B_{R}$ been followed by $O_{R}$ and $O_{G R}$. This diagram is thus no more than a schematic way of representing the, shall we say, (to use the term we theoretical psychologists have of late taken so violently to our bosoms) "operational" facts. The expression at the left is

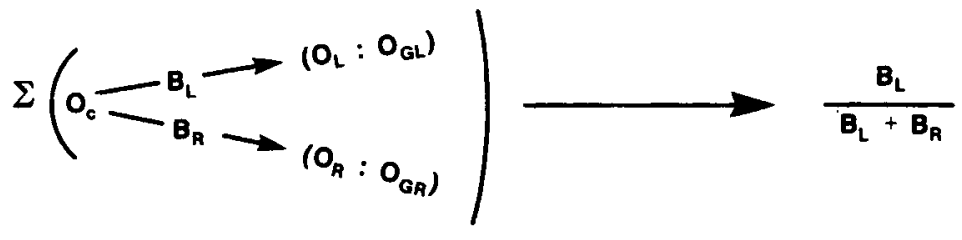



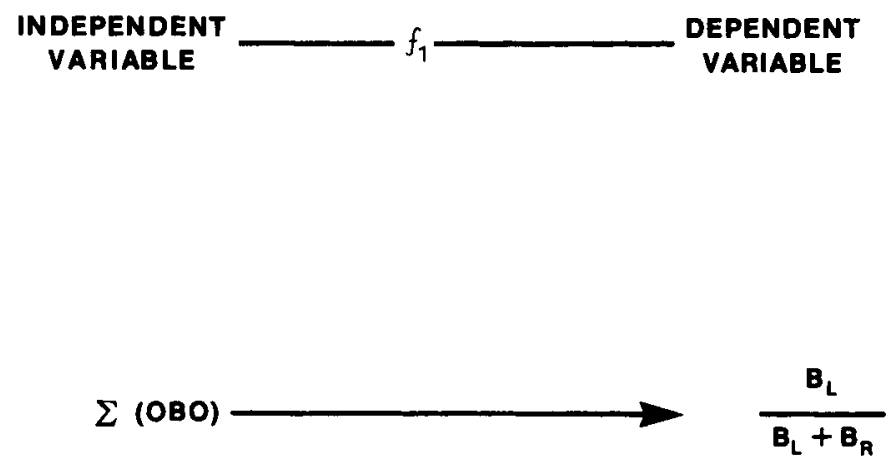

Figure 3.

an "operationally defined" independent variable and that at the right, an "operationally defined" dependent variable.

For brevity's sake, I shall often substitute, however, an abbreviated symbol for the left-hand term, viz.: simply $\Sigma(O B O)$, as shown in Figure 3.

One further point-the $f_{1}$ in each of these figures indicates merely the fact of the functional dependence of the dependent variable upon the independent variable. To indicate the "form" of this function we would require a more analytical diagram, such as that shown in Figure 4.

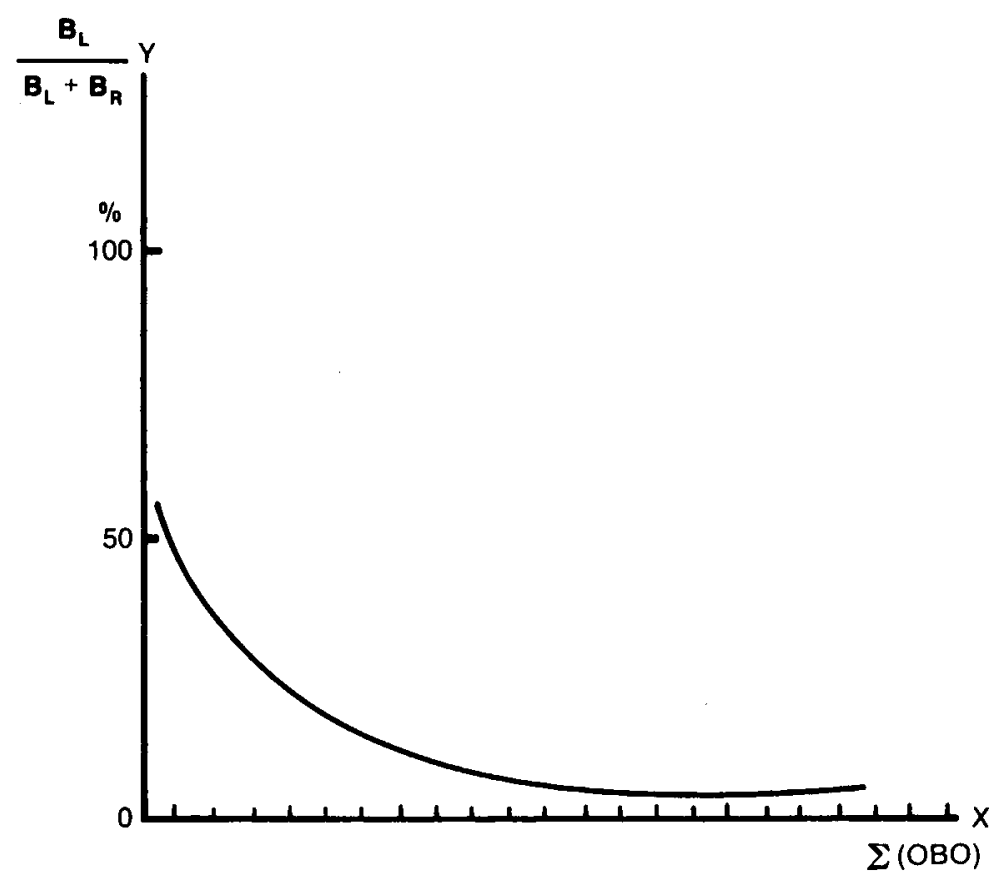

Figure 4. 
But this, or course, is no more than our old friend, the learning curve. It results when we plot the independent variable along an $X$ axis and the dependent variable along a $Y$ axis. Nothing very new so far. It seems surprising, however, that in spite of the thousands, not to say millions, of such learning curves which have been obtained in the last four decades in American rat laboratories there are still a variety of quite simple things about this function which we do not yet know or with regard to which we are still in dispute.

For example, we are still in dispute, first of all, as to the relative importance of the occurrences of the two alternative behaviors $B_{L}$ and $B_{R}$, where $B_{L}$ is "wrong" and $B_{R}$ is "correct." (See Figure 5.)

Thorndike $(118,119)$ and Lorge $(69)$ and their co-workers, as you all know, working with human beings in analogous, though verbal, set-ups have now concluded that the occurrence of the wrong behavior has no such general causative effect. They find that learning appears only as a result of the occurrences of the rewarded sequence $O_{C}-B_{R} \rightarrow\left(O_{R}: O_{G R}\right)$. On the other hand, still more recently, Muenzinger and Dove (95), working with set-ups similar to Thorndike's have found that the occurrence of the wrong response $O_{C}-B_{L} \rightarrow\left(O_{L}: O_{G L}\right)$ does weaken its tendency to re-occur. Also Carr, as a result of a series of experiments done by his students $(54,72,132,135,137)$ some time since in the Chicago laboratory, was finally forced to conclude that

. . . a certain number of errors must be made and eliminated before the subject is ever able to run the maze correctly. Correct modes of response are established in part by learning what not to do (16, p. 98 , italics mine).

A second point about which we are still surprisingly ignorant is that we do not yet know the importance of the rat's being permitted, or not

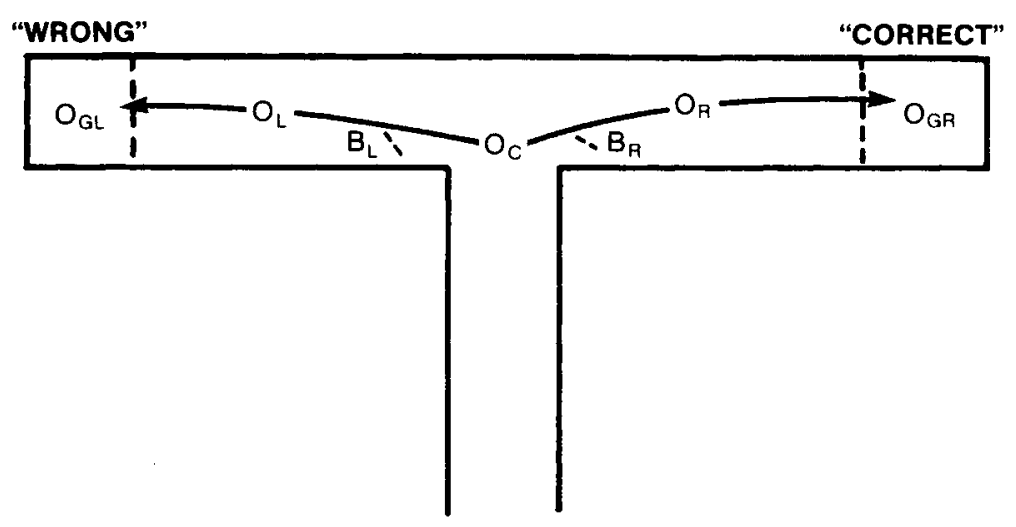

Figure 5. 
permitted, to return out of the wrong choice. In some experiments, when the animal takes the wrong alley, he passes through a one-way gate and is started over again. In others, he is allowed to treat it as a blind and back out. But, so far as I know, there has been no carefully controlled comparison between these two procedures.

Thirdly, the question of the relative effects of concentrated versus distributed repetitions has not as yet received the thoroughgoing experimental analysis that it deserves. But I understand that Professor Stone and his co-workers are now directing their attention to it and are getting some very significant findings.

Fourthly, we are ignorant concerning the difference between animals which have an initial left-hand bias and those which have an initial right-hand bias. ${ }^{1}$ We usually lump the results for both types together in a single curve. But we might well separate them and study them independently.

Fifthly, Brunswik (14) has recently brought to light a new point in our ignorance. He has been trying the effect of rewarding on the right and rewarding on the left different proportions of times. In other words, it was no God-given rule but apparently some merely human predilection on our part which made us heretofore tend almost invariably to make one of the alternative behaviors always rewarded and the other always punished. But other frequencies of reward and punishment are equally possible and equally deserving of study.

Sixthly, experiments by Krechevsky $(59,60,61)$, seem to indicate that there may be certain general features about the content of the OBO's such, for example, as their containing variable or non-variable paths, which are very important in determining the resultant behavior-ratios and about which we need more information.

Seventhly, a further point which needs more investigation is, as Muenzinger and his co-workers $(87,88,89,90,91,92,93)$ have beautifully brought out, the fact that punishment or obstacles to be overcome, even on the correct side, may sometimes seem to aid rather than hinder learning. (See also Tolman, 125, and Tolman, Hall and Bretnall, 127.)

Eighthly, there is the question of what happens when $\Sigma(O B O)$, the number of trials, has become very great. This seems to induce a special sort of result for which the term fixation has been suggested. ${ }^{2}$ And further studies of such "fixations" are needed.

Ninthly, the problem as to the effect of temporal intervals between $O_{C}$ and the resultant $O_{G L}$ and $O_{G R}$ are still by no means altogether completely worked out in spite of all the beautiful work of Hunter and

1. For one of the first experiments indicating that there are such biases, see Yoshioka (149).

2. See the original experiments on fixation by Gilhousen $(31,32)$, Krechevsky and Honzik (62) and Hamilton and Ellis $(28,38,39)$. 
his students, and others who have followed after, on the "delayed reaction" and on "double alternation." 3

Finally, however, there is a point with regard to which we are not altogether ignorant but the importance of which we usually overlooknamely, the fact that any such function-any such learning curve, actually, is always obtained within the matrix of a larger number of other independent variables in addition to $\Sigma(O B O)$. The following is a tentative list of such other variables together with $\Sigma(O B O)$ :

\section{Environmental Variables}

$M-$ Maintenance Schedule

G-Appropriateness of Goal Object

$S$-Types and Modes of Stimuli Provided

$R$-Types of Motor Response Required

$\Sigma(O B O)$ - Cumulative Nature and Number of Trials

$P$-Pattern of Succeeding and Succeeding Maze Units

2. Individual Difference Variables

$$
\begin{aligned}
& H \text {-Heredity } \\
& A-\text { Age } \\
& T \text {-Previous Training } \\
& E-\text { Special Endocrine, Drug or Vitamin Conditions }
\end{aligned}
$$

As you will see, I have divided such independent variables into two groups which I have called: (1) Environmental Variables, and (2) Individual Difference Variables. The environmental variables are $M$, the maintenance schedule, by which I mean time since food, water, sex, parturition, or the like, which in common parlance we would call the drive condition; $G$, the appropriateness of the goal-object provided at the end of the maze relative to this drive; $S$, the specific types and modes of stimuli which the maze provides; $R$, the specific kinds of motor response required of the animal in the maze; $\Sigma(O B O)$, the cumulative sum and manner of trials; and $P$, the general pattern of the maze, that is to say, the number and sorts of preceding and succeeding units. The individual difference variables are: $H$-heredity, $A$-age; $T$-previous training, and $E$ - any special endocrine, drug, or vitamin conditions.

But if, now, we are to include all these independent variables together with $\Sigma(O B O)$, we must have a new causal picture. I suggest the one shown in Figure 6.

A main causal line has been drawn, as you see, issuing from each environmental variable. And the individual difference variables, $H, A, T$, and $E$, have been arranged as possible modifiers of each such main causal line. And what I have hereby tried to indicate is merely the actual types of experiment which we maze-psychologists go in for.

3. The literature on these matters is, of course, already enormous and I can not pretend to quote it here. It will suffice to refer to Munn's chapter on "Symbolic Processes" (95, Ch. 7) and to Heron's chapter on "Complex Learning Processes" (40). 
INDEPENDENT VARIABLES

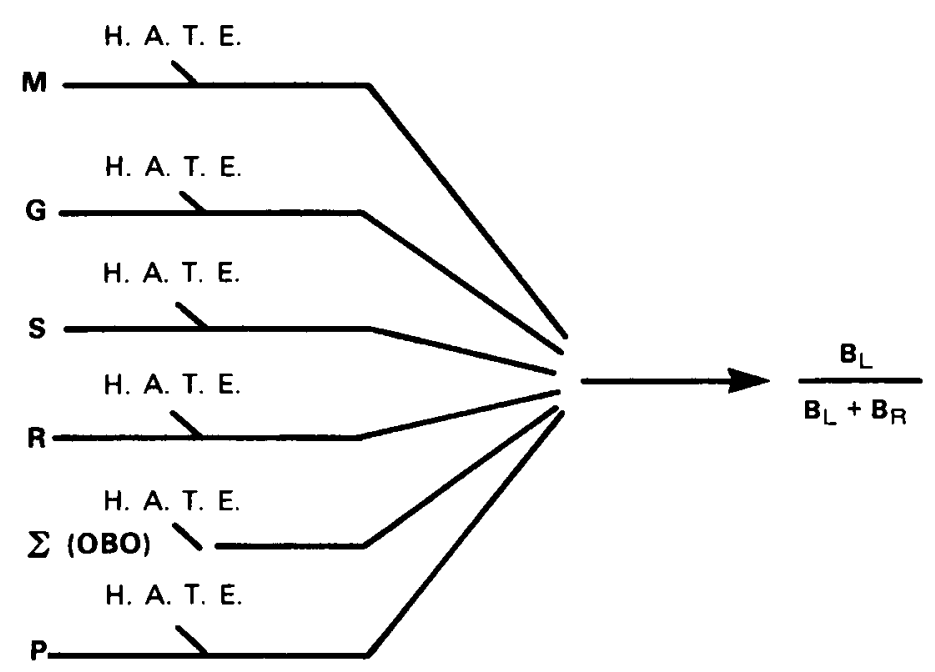

Figure 6.

I wish now, however, to pass from the above outline of experiments to a consideration of theories. But why, you may ask, can we not be satisfied with just experiments and the "facts" resulting from them $?^{4}$ I find that there are two reasons. In the first place, an entirely factual, empirical establishment of the complete functional relation, $f_{1}$, to cover the effects on $B_{L} /\left(B_{L}+B_{R}\right)$ of all the permutations and combinations of $M$, $G$, $S$, etc., etc., would be a humanly endless task. We have time in this brief mortal span to test only a relatively limited number of such permutations and combinations. So, in the first place, we are forced to propose theories in order to use such theories to extrapolate for all these combinations for which we have not time to test.

But I suspect that there is also another reason for theories. Some of us, psychologically, just demand theories. Even if we had all the million and one concrete facts, we would still want theories to, as we would say, "explain" those facts. Theories just seem to be necessary to some of us to relieve our inner tensions.

But what is a theory? According to Professor Hull (49), a theory is a set of definitions and postulates proposed by the theorist (on the basis presumably of some already found facts) from which other empirically testable facts, or as he calls them, theorems, can be logically deduced. These deduced theorems will be new empirical relationships which the

\footnotetext{
4. That the facts must be obtained first of all and that we psychologists have for the most part been both extremely lazy and extremely shoddy in our pursuit of the "facts" has been eloquently pointed out by Brown (12).
} 


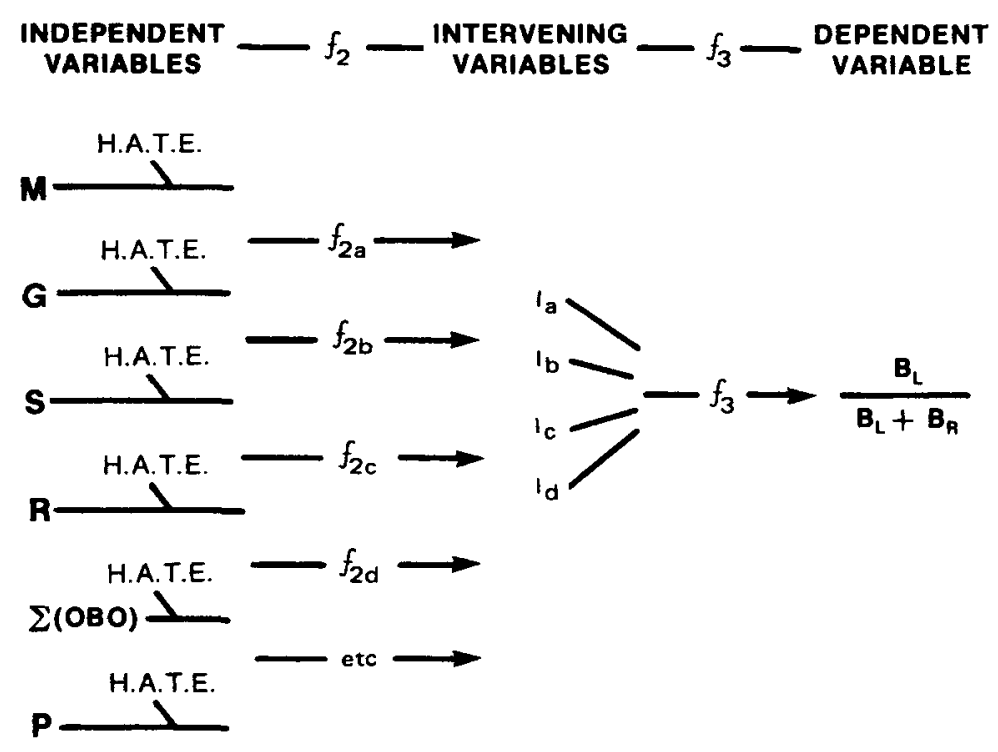

Figure 7.

theorist-or more often, his research assistants-can, then and there, be set to look for.

For my own nefarious purposes, however, I wish to phrase this matter of the relationship of a theory to the empirical facts out of which it arises and to which it leads in somewhat other terms. A theory, as I shall conceive it, is a set of "intervening variables." These to-be-inserted intervening variables are "constructs" which we, the theorists, evolve as a useful way of breaking down into more manageable form the original complete $f_{1}$ function. In short, I would schematize the nature of our psychological theories by Figure 7 . In place of the original $f_{1}$ function, I have introduced a set of intervening variables, $I_{a}, I_{b}, I_{c}$, etc., few or many, according to the particular theory. And I have conceived a set of $f_{2}$ functions to connect these intervening variables severally to the independent variables, on the one hand, and an $f_{3}$ function to combine them together and connect them to the final dependent variable, on the other. ${ }^{5}$

But turn, now, to some of the actual theories. I shall restrict myself to the discussion of three-Professor Thorndike's, Professor Hull's, and my own. This, or course, will hardly be a fair survey of the field. There are many other doctrines of learning, as, for example, Professor Guthrie's (33), and those of the other conditioned reflex psychologists $(145)^{6}$ and those of the Gestalt school, (2), (45), (55), (56), (143), which are of as great 126).

5. For previous presentations of this notion of "intervening variables" see Tolman (124,

6. For a superb presentation and summary of all the conditioned reflex theories of learning see Hilgard (44). 


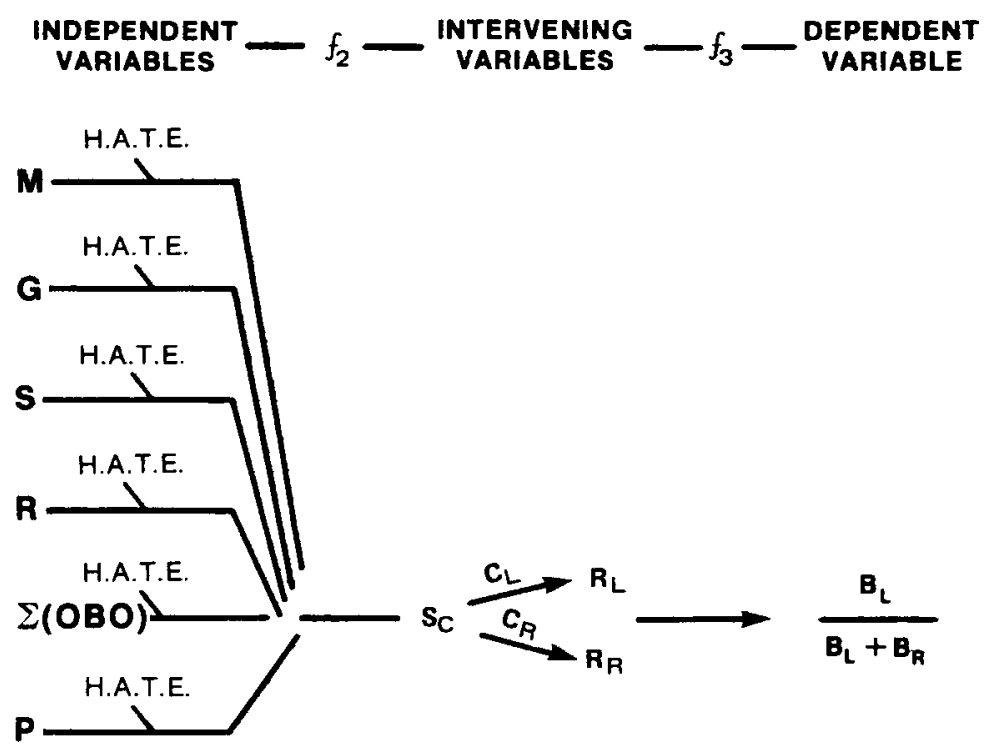

Figure 8.

importance and which have equally affected by own thinking. But I shall have to omit a discussion of them here.

Professor Thorndike's "intervening variables" are quite simple. They are "stimuli," "bonds" or "connections," and "response-tendencies." His theory I would represent, therefore, by the diagram shown in Figure 8. It is Thorndike's conception of the nature of the $f_{2}$ function which seems to be the crux of his theory. Originally, his statement of this function included both a Law of Exercise and a Law of Effect. But now, as we all know, it includes a Law of Effect only, and a truncated law at that. For, as now stated, Thorndike finds that it is the repetitions of the rewarded sequence $O_{C}-B_{R} \rightarrow\left(O_{R}: O_{G R}\right)$ which alone are important. These strengthen the $C_{R}$ connection. The repetitions of the punished $O_{c}-B_{L} \rightarrow\left(O_{L}: O_{G L}\right)$ sequence do not, he says, correspondingly weaken the $C_{L}$ connection.

I have quite a number of quarrels with this theory. I would like to say first, however, that it seems to me that this theory of Thorndike's either in its present or in its earlier form, is the theory relative to which the rest of us here in America have oriented ourselves. The psychology of animal learning - not to mention that of child learning-has been and still is primarily a matter of agreeing or disagreeing with Thorndike, or trying in minor ways to improve upon him. Gestalt psychologists, condition-reflex psychologists, sign-gestalt psychologists-all of us here in America seem to have taken Thorndike, overtly or covertly, as our starting point. And we have felt very smart and pleased with ourselves if we could show that we have, even in some very minor way, developed new little wrinkles of our own. 
Let me now, nonetheless, try to present my criticisms. First, Thorndike's theory, as I see it, identifies stimuli ( $\left.S^{\prime} s\right)$ with gross objects $\left(O^{\prime} s\right)$ and identifies specific muscular responses $\left(R^{\prime} s\right)$. with gross means-end behaviors $\left(B^{\prime} s\right)$. And this procedure seems to me to require more justification than he gives it. It raises the problem of "equivalence of stimuli" and "equivalence of response" which Klüver (53), Waters (138), and others have been concerned with. It is also probably connected with the problem of perception-constancy which the Gestalt psychologists and other Europeans have dealt with at such length. ${ }^{7}$

My second objection is that the theory as stated by Thorndike does not allow for the facts of "latent learning," of the complementary phenomenon of a sudden shoot-up in errors when a goal is removed, and of the utilization of alternative habits under different motivations. That, to allow for these facts, a distinction must be made between "learning" and "performance" has indeed already been emphasized by Lashley (63), Elliott (27), Leeper (64) and myself $(122,123)$. But Thorndike's theory allows no such distinction.

Finally, my third objection is that the theory does not, for the most part, make anything of the other circumambient variables $M, G, S$, etc., in addition to $\Sigma(O B O)$. No doubt Thorndike, if this were pointed out to him, would try to work all these other independent variables in as further conditions tending to favor or hinder the respective strengths of $C_{R}$ and $C_{L}$. But my suspicion is that he would have difficulty.

Turn, now, to Professor Hull's theory. For Hull the intervening variables are "conditionings" of the running responses to successive aggregates of exteroceptive, proprioceptive, and interoceptive stimuli. In order to explain this, first let me present another picture of the simple $T$ maze (Figure 9).

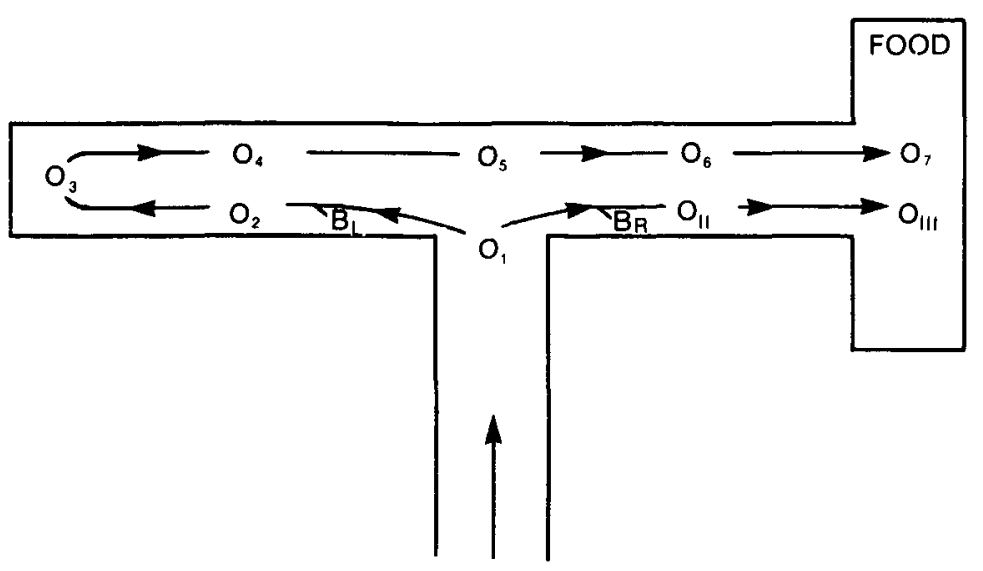

Figure 9. 
Two alternative routes are shown-one in which the animal goes directly down the true path and one in which he first chooses the blind to the left. Successive points along these two paths are indicated as successively numbered $O^{\prime}$ s. The true path involves three such $O^{\prime}$ s, the blind alley, seven, and, to explain the tendency which develops in such a situation to go right rather than left, Hull's theory postulates the intervening variables shown in Figure 10.

What I have done, as you will see, is to insert one of Hull's own diagrams $(48,44)$ in the middle and to call it his set of intervening variables. You are all familiar with such diagrams. They are very clever and can be invented, as I know to my cost, to explain practically any type of behavior, however far distant from an instance of conditioning such a behavior might at first sight appear. I have, therefore, the greatest respect for them. And, even though I argue against them, I find myself continually being intrigued and almost ready to change my mind and accept them and Hull after all.

It must be noted further, however, that there are certain other concepts besides conditioning involved in these diagrams which help to make them work. These seem to be: (1) anticipatory goal-responses, i.e., the little $r_{G}$ 's with their little resultant proprioceptive or interoceptive $s_{G}$ 's whereby the character of the goal is brought back into the aggregates of conditioned stimuli at the different points along the maze; (2) the continuous drive stimulus $S_{D}$ which also appears at all points and thus also becomes part of the total conditioned stimulus-aggregate at each point along the maze paths; (3) the goal-gradient hypothesis whereby all conditionings are stronger the nearer they are to the goal; and (4) habitfamily hierarchies whereby, if one path or route is blocked, the rat readily switches over to any alternative chain of conditionings which he has at his command. By virtue of these concepts, in addition to that of conditioning per se, Professor Hull is able to bring into his diagram the influences not only of $\Sigma(O B O)$ but also of $M$, maintenance schedule; $G$, goodness of goal; and $P$, maze-pattern, in a rather remarkable way. He has not, on the other hand, as I see it, especially considered as yet the variables $S$, and $R$, and $H, A, T$, and $E$.

I have four rather specific criticisms of Hull's theory. First, Hull, like Thorndike, passes from $O$ 's and $B^{\prime}$ 's to $S^{\prime} s$ and $R$ 's with no clear statement of his justification for doing so. And, again, $I$ feel, as $I$ did relative to Thorndike, that, if such simple $S-R$ formulations are to have cogency, we must be told why and how the actual gross $O$ 's can be reduced to simple $S$ 's, and the actual gross means-end $B$ 's to simple $R$ 's.

My second criticism lies in the fact that I doubt that the supposed laws of conditioning are as simple and as well-known as Hull assumes. Many of the actual workers in the field, for example Loucks $(70,71)$, Liddell (67), Culler (21), Schlosberg (105, 106), Hilgard (42, 43) seem to find conditioning a very variable and complicated phenomenon. To explain maze behavior by conditioning seems to me, therefore, like asking the halt to lead the blind. Or to put this another way, what Skinner (108) (see Figure 11) calls his Type 1 sort of conditioning (which 


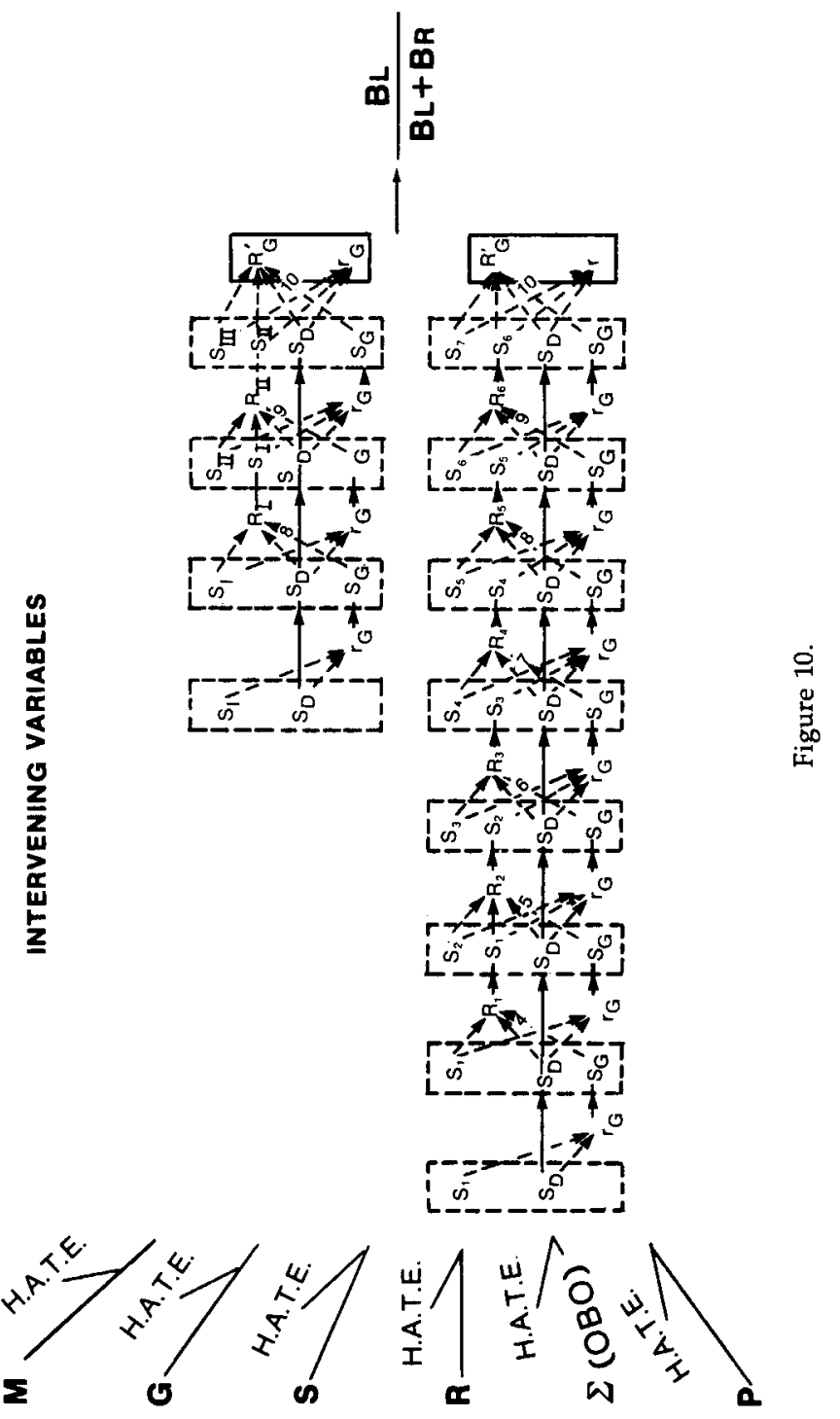


TYPE 1

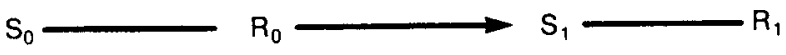

TYPE II

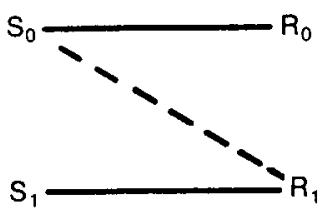

Figure 11.

for me is not conditioning at all) seems to be at the present stage of the game, just as well and perhaps better understood than the more classical, or what he calls his Type 2, sort of conditioning.

Finally, when it comes to using one of Hull's diagrams for actually predicting, on any given occasion, the value of $B_{L} /\left(B_{L}+B_{R}\right)$ I find that the difficulty of determining the actual strengths to be assigned to the various $S-R$ connections an almost insuperable one. But, then, perhaps an analogous sort of criticism will be raised against my diagrams. So, in conclusion, let me repeat that I have a tremendous respect for Professor Hull's theory and that I am not by any means as yet altogether certain that mine is better.

I come, now finally, to my own theory. But first, I would like to make it clear that however complicated what I am actually going to present may appear, it will be in reality an over-simplified and incomplete version. Partly for the sake of simplicity and partly also, I suppose, because I have not as yet completely thought the whole thing through, the diagrams I shall present will not contain as many "intervening variables" nor as complicated interfunctional relations as, I suspect, will finally actually prove necessary. They will, however, indicate the general picture.

My first diagram would be that shown in Figure 12.

Note the list of intervening variables: "demand," "appetite," "differentiation," "skill," "hypotheses," and "biases." 8 Such concepts are, I am sure, irritating in that they appear subjective and not the sort to be

8. In addition to these the final version of the theory would, 1 suspect, have to add other intervening variables such as: "general activity," for the best discussion of this which I know see Munn (97, Ch. 2); General attentivity or "vigilance," see Krechevsky (58); and demand for "parsimony"-i.e., demand against "distance" and "barriers," see, for example, Tolman (122, Ch. 7), Gengerelli (30), McCulloch (84), Tsai (133), Waters (140), Wheeler (143) and Wright (148). 


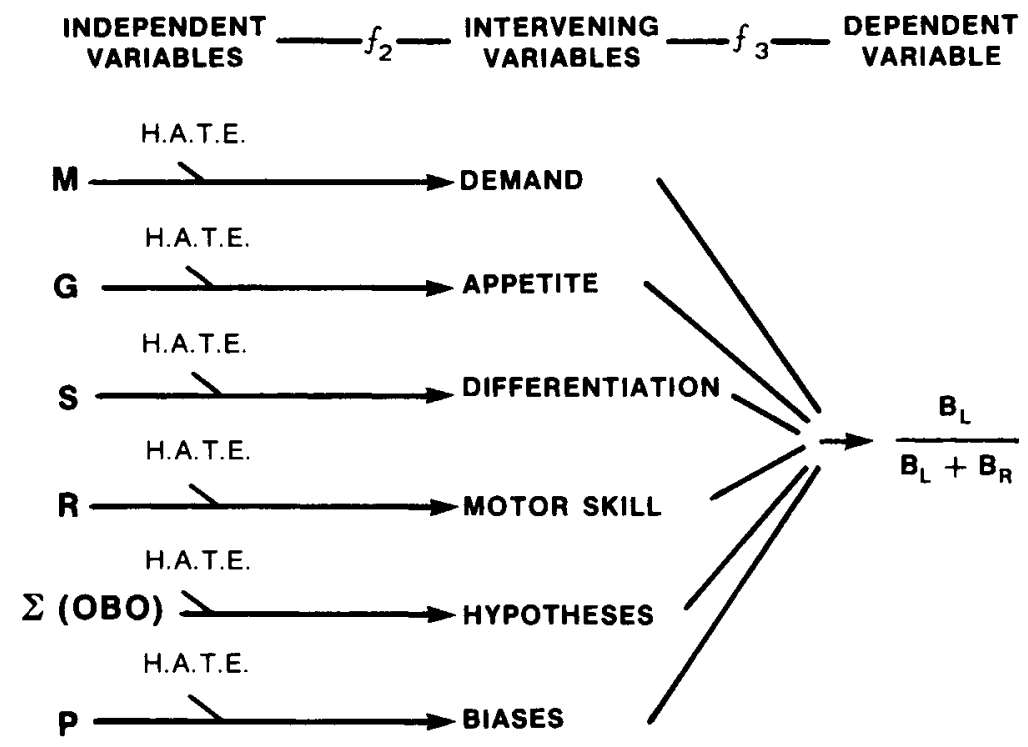

Figure 12.

permitted in an honest behaviorism. Each of them is, nonetheless, I would claim, capable of a perfectly objective definition and measurement. Thus, you will note that each is depicted as resulting from its own correlative environmental variable plus the controlling effects of $H, A, T$, and $E$. "Demands" result from $M^{\prime}$ 's; "appetites" from $G$ 's; "differentiations" from $S$ 's; "skills" from $R$ 's; "hypotheses" from $\Sigma(O B O$ 's); and "biases" from $P$ 's. And I am now going to assert that each such "intervening variable" is defined by a standard experiment in which its correlative independent environmental variable is systematically varied. Further, in each such experiment all the other independent variables are held constant while the one in question is systematically changed. Under such conditions the resultant variations in $B_{V}\left(B_{L}+B_{R}\right)$ are, by definition, to be said to mirror directly the variations in the one given intervening variable.

For example, the intervening variable-"demand"-(say for food) shall, by definition, be measured by the variations in the behavior-ratio which occur in a standard experiment when $G$ and $S$ and $R$ and $\Sigma(O B O)$ and $P$ and $H$, and $A$, and $T$, and $E$, that is, all the independent variables other than $M$, are held constant at certain "standard" values, while $M$, itself, is systematically varied. For example, as standard values for these other variables I should probably choose: for $G$ the regular standard living diet of the colony, for $S$ an elevated maze in which all possible visual, olfactory, auditory, tactual and kinaesthetic stimuli would be available, for $R$ a maze which involved running rather than swimming, or climbing, or going hand over hand, or pulling strings, or what not, for $\Sigma(O B O)$, that set-up which makes the left-hand side a blind and a distribution of one trial every 24 hours, and a number of trials which, for 


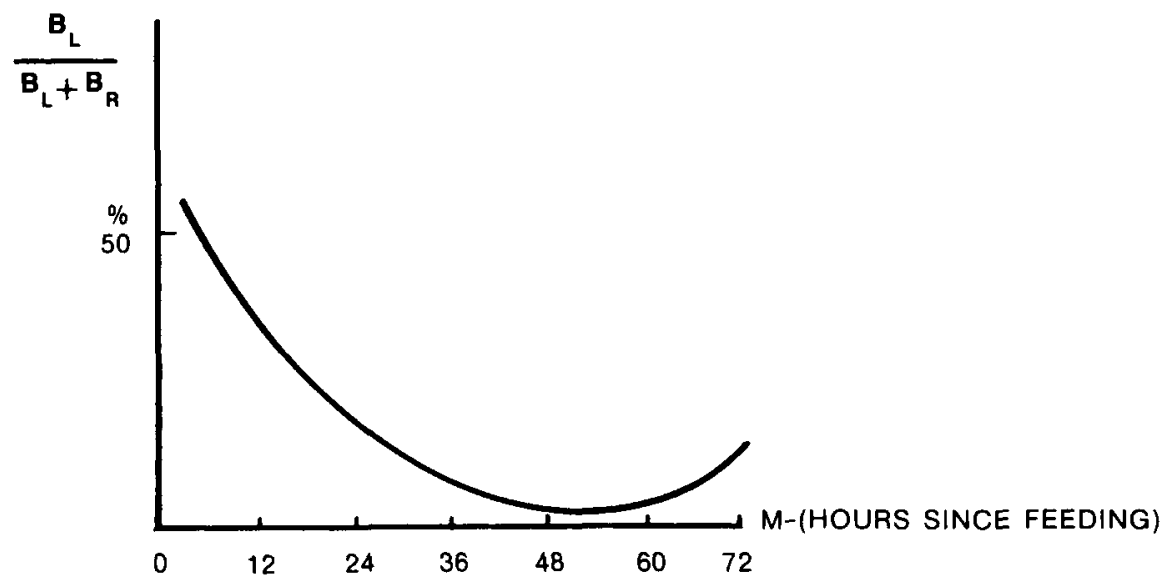

Figure 13.

an average value of $M$, would bring the learning curve about down to the base line-say some 10 trials-and for $P$ a single-unit $T$ with no preceding or succeeding units. With such a set-up in which all the other independent variables would thus be given these standard values and held constant, I would then vary $M$ and study the correlated variations in $B_{L} J\left(B_{L}+B_{R}\right)$. And the sort of results one would get are shown in Figure 13.

But the demand should really be defined as inversely related to this $B_{L} /\left(B_{L}+B_{R}\right)$ ratio, so that replotting one would have as one's final defining function that shown in Figure 14. And having, thus at last, this

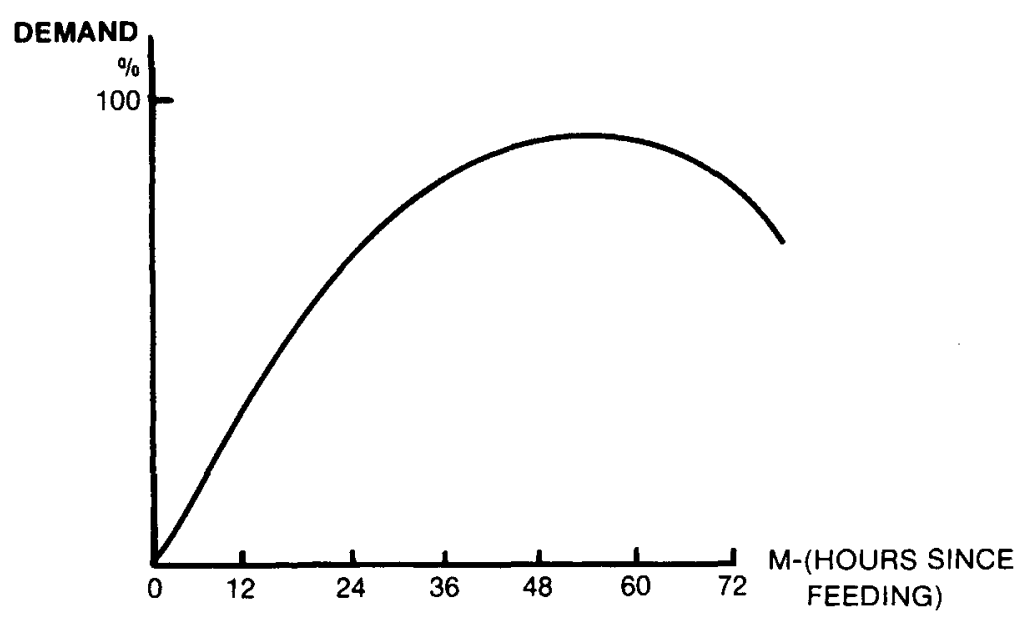

Figure 14. 


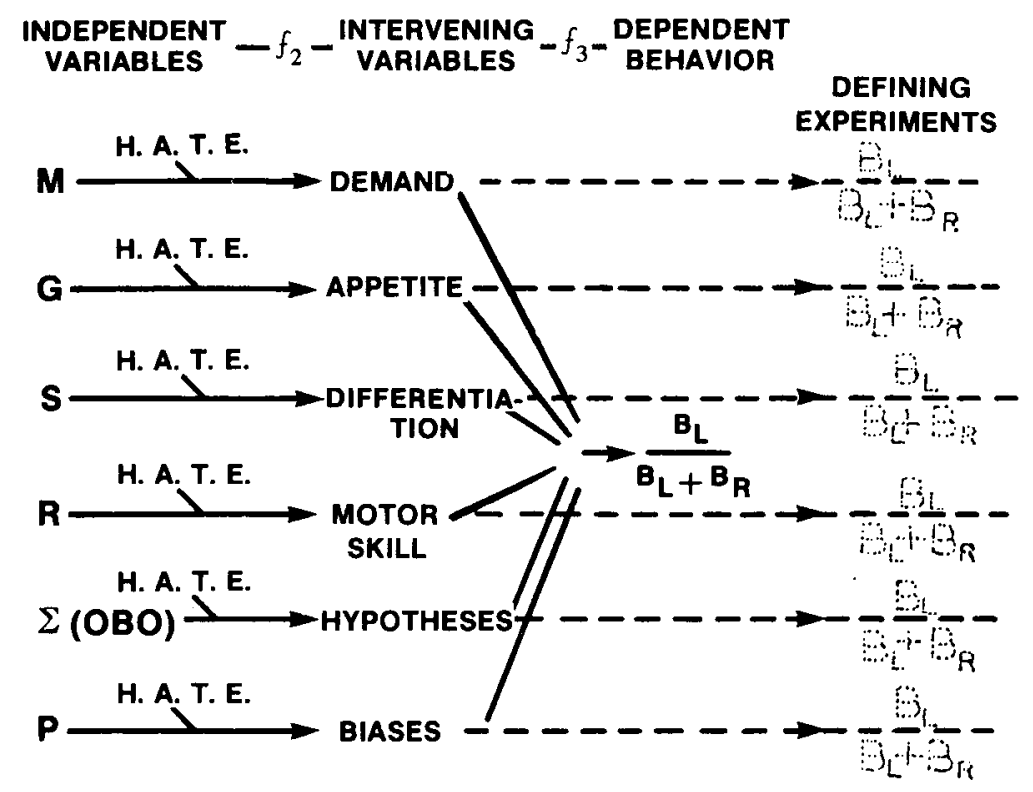

Figure 15.

curve-this $f_{2}$ function-between $M$ and "demand" one would use it for defining the to-be-assumed value of the demand for any given value of $M$ on all future occasions.

But this procedure, which I have thus outlined in some detail for demand, could also be used in analogous fashion for defining each of the other intervening variables. For each of them, also, we could set up a defining experiment in which all the independent variables other than the correlative one, would be held constant while that one was systematically varied. And we would obtain in each case a resultant defining curve or table. Figure 15 schematizes the fact of such possible defining procedures.

A brief review of the literature would suggest that many such defining experiments have already been done. Under "demand" we think at once of Warden and his co-workers (136), and of Elliott (26). Under the heading of "appetite" we think of Young $(151,152,153)$, Elliott (25) and Bruce (13), and for an extraordinarily good summary of all the work relative to both demands and appetites we would look to Stone's chapter in Moss's "Comparative Psychology" (115). Under the heading of "differentiation" we think of many individuals: Watson (141), Carr $(17,18,19)$, Hunter $(50,51)$, Dennis (24), Casper (20), Lindley (68), Wolfle (147), and Honzik (46), to mention only a few. Under the heading of "motor skill" we think of Macfarlane (73). Under that of "hypotheses" we think of practically all rat-runners in the world but for the final indignity of suggesting such a term as "hypotheses" we must blame 
Krechevsky (57). ${ }^{9}$ And finally, under "biases" we think of Dashiell (22), Bayroff (6), Dashiell and Bayroff (23), Schneirla (107), Yoshioka (149, 150), Ballachey and Krechevsky (5), Spence (110), Spence and Shipley (111), Spragg $(112,113)$, Buel $(7,8)$, Ballachey and Buel $(3,4)$, Buel and Ballachey $(10,11)$, Ruch $(100,101,102,103)$, Waters (139), and Witkin and Schneirla (146); and not even this completes the list.

Finally, turn to the $f_{3}$ function. It is by means of this $f_{3}$ function (if we but knew what it was) that we would be able to predict the final outcome for all possible values of the intervening variables. It would allow us to predict the result of every possible strength of "demand" combined with every possible degree of "appetite," with every possible goodness of "differentiation," and so on. That is to say, the $f_{3}$ function, if we but knew it, would provide a set of rules by which to predict for all these million and one possible combinations. It would consist in some equation, geometrical picture, or what not, which would give the way of adding together the different values of these different variables. But here, alas, I confess is the feature of my doctrine about which I am, to date, haziest. I would venture, however, a few suggestions.

First I would assert that the implicit assumption of most other psychologists is to the effect that their $f_{3}$ functions are in the nature of simple algebraic summations. That is to say, these others seem to assert that a poor demand would be compensated for by a good hypothesis, a poor skill by a strong differentiation, a poor differentiation by a strong appetite, and the like. Indeed it seems to me that all the associationistic psychologies, whether they be of the trial-and-error variety or of the conditioned reflex variety really imply just such simple algebraic summations. What I have distinguished as "demands," "appetites," "differentiations," "skills," "hypotheses," and "biases" the associationistic psychologies have lumped together, one and all, as mere $S-R$ 's. If the rat be very hungry (have a strong demand) this, for them, is but an enhancement of some $S-R$ connection; if he have a strong appetite as a result of the type of goal presented, this also is but some $S-R$, stronger than it otherwise would have been; if the given maze-bifurcation present lots of stimuli (leads to clear differentiations) again, merely some $S-R$ 's are stronger; if the maze be constructed to require unusual motor skill from the animal, this again means merely a strengthening (or in this case probably a weakening) of some bond or other; if $\Sigma(O B O)$ has become large-if, that is to say, the hypotheses have become "developed and sure" this also means but better $S-R$ connections; and finally, if the maze be shaped to induce, say, a strong centrifugal swing to the right or a strong forward-going tendency to the left, this, also is for them, but a matter of the strengthening of one or another $S-R$ bond. And the final

9. See also the problems concerning this $f_{2}$ function between $\Sigma(O B O)$ and hypotheses already discussed above. 


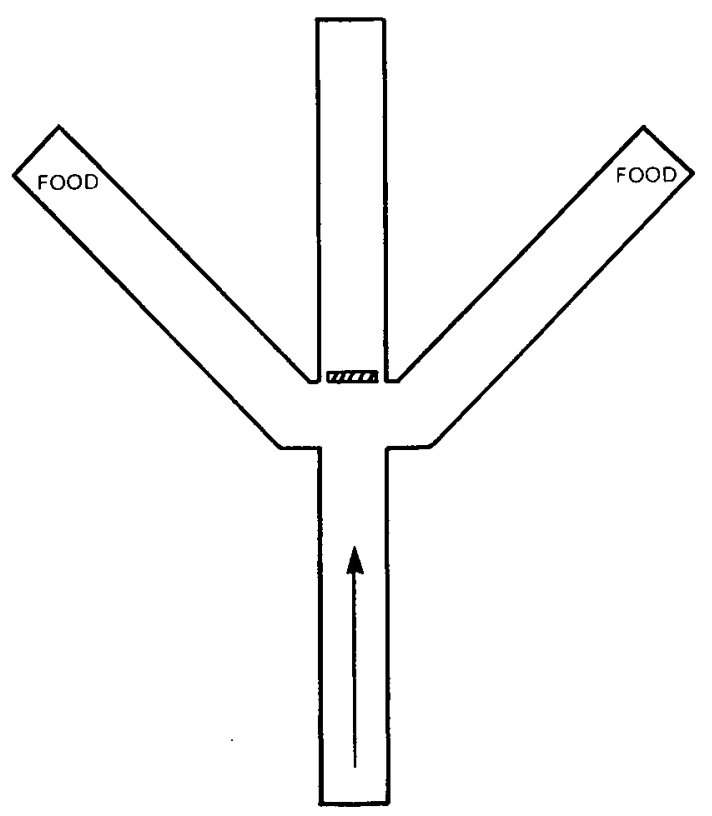

Figure 16.

value of the resultant behavior-ratio is then obtained by all such psychologies by a simple toting up of these plus and minus, strong and weak, $S-R$ bonds. But I am very doubtful of the adequacy of any such simple type of additions.

Let me recall again the facts of "latent learning." During latent learning the rat is building up a "condition" in himself, which I have designated as a set of "hypotheses," and this condition-these hypotheses-do not then and there show in his behavior. S's are presented, but the corresponding $R^{\prime} s$ do not function. It is only later, after a goal has been introduced which results in a strong appetite, that the $R^{\prime} s$ or as I would prefer to say, the $B^{\prime} s$, appropriate to these built-up hypotheses appear. So long as there is no appetite for what is found at the end of the maze, strong demands, plus strong hypotheses do not add up at all. A strong hypothesis and a strong demand do not compensate for a weak appetite. And a strong demand and a strong appetite cannot in their turn overcome a weak hypothesis. And so on. The ways of combination of the intervening variables do not seem those of simple scala addition.

Or consider, as another example, the addition of two hypotheses. And suppose that instead of the usual two-way choice-point, we had one such as that shown in Figure 16. In this set-up after a long series of preliminary training in which only the two side-paths were open, the middle path was also opened up (I refer here to an actual experiment devised and carried out at California by Mr. R. S. Crutchfield). As a result of the preliminary training the two hypotheses of food to the left and food to the right were built up. It appeared, however, in the test 


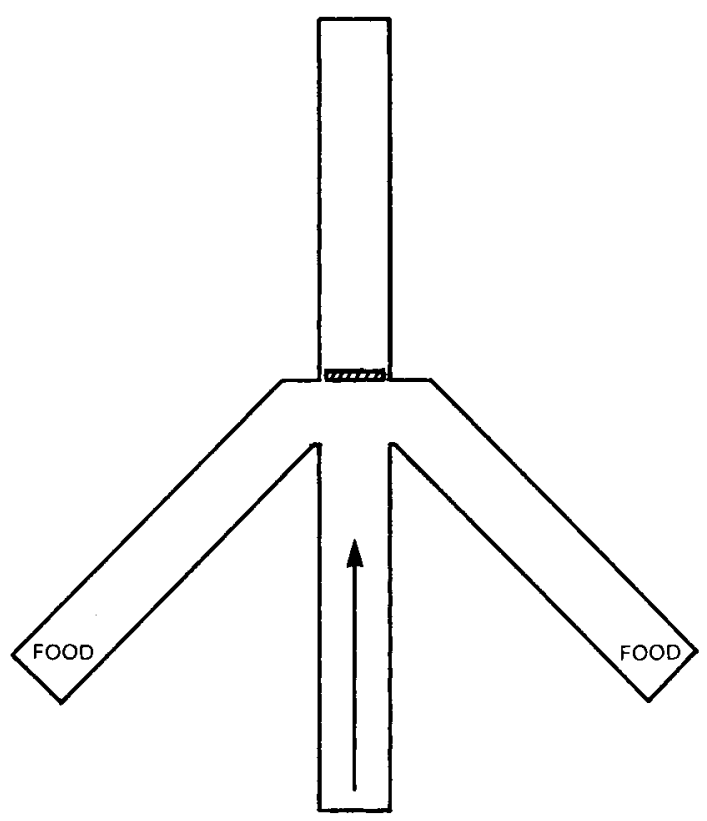

Figure 17.

runs, that these then added together in such a way as to make a very strong resultant tendency to go straight ahead when the third central path was opened-in short, a very much stronger tendency to go ahead than was found to have resulted from the two hypotheses which got built up when in another set-up the two side paths were as shown in Figure 17. The laws of the addition of hypotheses here appeared, in short, not as scala and algebraic, but as vectorial.

Or, again consider the facts of rat behavior which ordinarily go under the names of "insight" and reasoning, that is to say, such facts as have been gathered by Honzik and myself $(128,47)$ and by Maier $(74,75$, $76,77) .{ }^{10}$ These are again, as I see it, also primarily facts concerning the addition of hypotheses. The addition here also is anything but simple and algebraic.

And so I am brought finally to my present confession of faithnamely, that Professor Lewin's topological and dynamic concepts $(65,66)$ now seem to me the best lead that $I$ have at present for conceiving the nature of this $f_{3}$ function. I neither understand nor approve them in their entirety. And, if I were clever enough, I should undoubtedly try in many ways to improve upon them. But nonetheless, even as they are, they seem to me by far the most stimulating and important ideas which have appeared in psychology (that is, in pure psychology, as distinct from physiology or embryology) in the past decade. 
One final point, concerning my thinking about the $f_{3}$ function. I am at present being openly and consciously just as anthropomorphic about it as I please. For, to be anthropomorphic is, as I see it, merely to cast one's concepts into a mold such that one can derive useful preliminary hunches from one's own human, everyday experience. These hunches may then, later, be translated into objective terms. But there seems to me every advantage in beginning by conceiving the situation loosely and anthropomorphically. I might never have arrived at this point of view of accepting anthropomorphism as a perfectly proper heuristic procedure all by myself. And I certainly would hardly have dared advance such a view publicly, if it had not been for the counsels of several other psychologists, especially Professors Liddell and Zener. But, in any case, I in my future work intend to go ahead imagining how, if I were a rat, I would behave as a result of such and such a demand combined with such and such an appetite and such and such a degree of differentiation; and so on. And then, on the basis of such imaginings, I shall try to figure out some sort of $f_{3}$ rules or equations. And then eventually I shall try to state these latter in some kind of objective and respectable sounding terms such as vectors, valences, barriers, and the like (to be borrowed for the most part from Professor Lewin).

Also, of course, I shall try to do experiments similar to those of Lewin and his students in which these intervening variables (as extrapolated from their correlative independent variables) are given such and such supposed values and then the final behavioral outcomes measured. ${ }^{11}$

But many of you must have been asking yourselves all this time: what about the $H, A, T$, and $E$ variables? In the defining experiments I have suggested so far, which have been concerned primarily with the environmental variables, these "individual difference variables" are assumed to have been given average standard values. We rat-workers have always done this, perhaps unconsciously. We have tried to keep heredity normal by using large groups, age normal by using rats between 90 and 120 days old, previous training normal by using fresh rats in each new experiment, and endocrine and nutritional conditions normal by avoiding special dosages and also again by using large groups.

But suppose, now, our intersts be in individual differences, per se. What experiments do we carry out then? It seems to me that individualdifference psychologists here tend to do two sorts of things.

On the one hand, they attempt (as do we environmental psychologists) to manipulate their independent variables for whole groups of animals and to get correlated variations in $B_{L} /\left(B_{L}+B_{R}\right)$. Thus they vary

11. As a beginning in this direction we already have some rat experiments by Hall (34, $35,36)$ and Hall and Ballachey $(37)$, and a recent set of experiments by Wright (148), but the latter were done unfortunately, from my point of view, not upon rats but upon children. But analogous experiments could, I believe, be done with rats. 
heredity, $H$, as Tryon (129) and Heron (41), and Rundquist (104) have done in controlled ways for large groups and get corresponding variations in this behavior-ratio, for such groups. Or, they vary age, $A$, as Stone and his students have done (114), also for large groups and again get corresponding variations in the behavior-ratio. Or, they vary previous training, $T$, that is, they study the effects of transfer-and here we have all taken pot shots-the first important experiment was, perhaps, that of Webb (142) and the last seems to be that of Bunch and Rogers (15) - and again attempt to get corresponding variations in the behaviorratio. Or, finally, they vary drugs, endocrines and vitamins, $E$, and get correlated variations in $B_{L} /\left(B_{L}+B_{R}\right)$. Here there are too many experiments for me to attempt to list them. ${ }^{12}$

Secondly, however, the individual difference psychologists have also done another more characteristic type of experiment. They have accepted from God, and from the accidents of miscegenation and of nursery schools, very large heterogeneous samples of rats and then they have put each such sample through a miscellaneous assortment of experiments (i.e., the different types of mazes that, in American rat-culture, are required of young rats in school, and also the different types of maze, discrimination-box, food, times since eating, and the like, which are required of old rats in polite society); and then they have obtained correlations and worked out factor analyses. And, finally, these individual-difference psychologists have ended up with their notions concerning the number and nature of the fundamental traits or capacities-"The Vectors of Mind" (120). These traits or capacities are, of course, but a new type of intervening variable and it would be nice, for me, if they fitted in neatly with the sort of intervening variables already suggested. They could then be put into my diagram as shown in Figure 18. But, alas, at present the results of factor analysis do not seem to suggest any such simple or agreed-upon results. You all know how the controversy rages from Spearman's one or two factors (109) through Kelley's (52) and Thurstone's (120) three to nine factors, differing somewhat in each setup $^{13}$ to Thorndike's $(116,117)$ and Tryon's $(131)$-God only knows how many. ${ }^{14}$

By way of conclusion, I want now, however, to turn to one wholly new point. I want to suggest that there also appear in maze behavior types of activity other than the simple $B_{L}$ 's and $B_{R}$ 's which we have thus

12. One of the best known early experiments was that of Anderson and Smith (1) on the effect of insufficient diets. And recent further important experiments on diet are those of Maurer $(78,79,80)$, and Maurer and Tasi $(82,83)$, Bernhardt (7), Muenzinger and the Poes $(96,98,99)$. For recent important experiments on drugs, see Miller and Miles (85) and Williams and O'Brien (144). Also for a summary, see Moss's own chapter in "Comparative Psychology" (86).

13. I think here of Vaughn's recent important monograph (120) in which he finds eight factors governing maze behavior.

14. For a general discussion of the problem of individual differences in animals see, also, Tryon (130). 


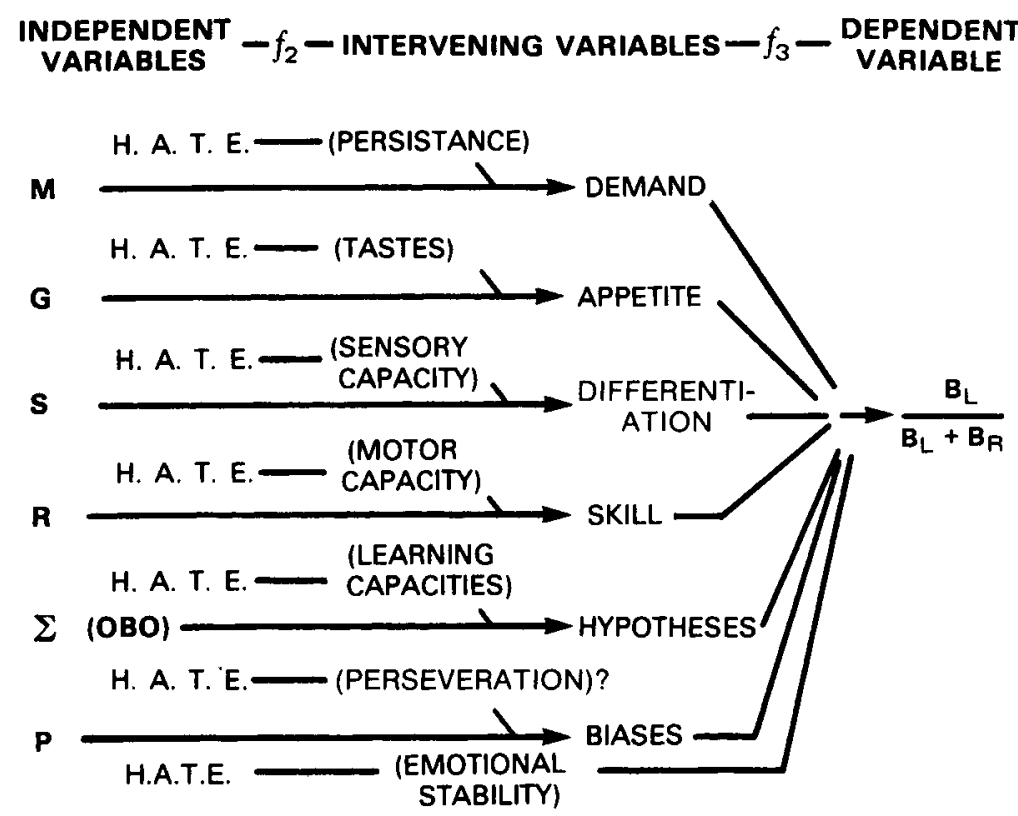

Figure 18.

far talked about. If these latter be called "achievement behaviors," then these new types of activity which I now have in mind, may be called "catalyzing behaviors." And it seems that we rat psychologists have to date rather pigheadedly (i.e., like Professor Liddell's pigs) ignored such catalyzing behaviors.

I have two instances which I would here like to call to your attention, although I believe that in the future technological advances in recording will bring to the fore many others for study. The first of these two examples consists of those "lookings or runnings back and forth" which often appear at the choice-point and which all rat-runners have noted, but few have paid further attention to. And the second type is that disrupted sort of activity which appears when a previously obtained goal object is removed or blocked. Let me begin with the former.

A few years ago $(121 ; 122$, Chap. 13) I had the temerity to suggest that such "lookings back and forth" might be taken as a behavioristic definition of conscious awareness. This was, no doubt, a silly idea. I would hardly dare propose it now. But, at any rate, such behavior is interesting and deserving of further study. Anthropomorphically speaking, it appears to be a "looking before you leap" sort of affair. Klüver (53) and Gellerman (29) have recorded it in connection with the behavior of monkeys, chimpanzees and children. And, further, I have recently learned that Professor Muenzinger and his students have also been keeping records of it in rats and that they have called it "vicarious trial and error"-or, more briefly, VTE. I shall, therefore, designate such behavior as VTE or $B_{V T E}$ from here on. 


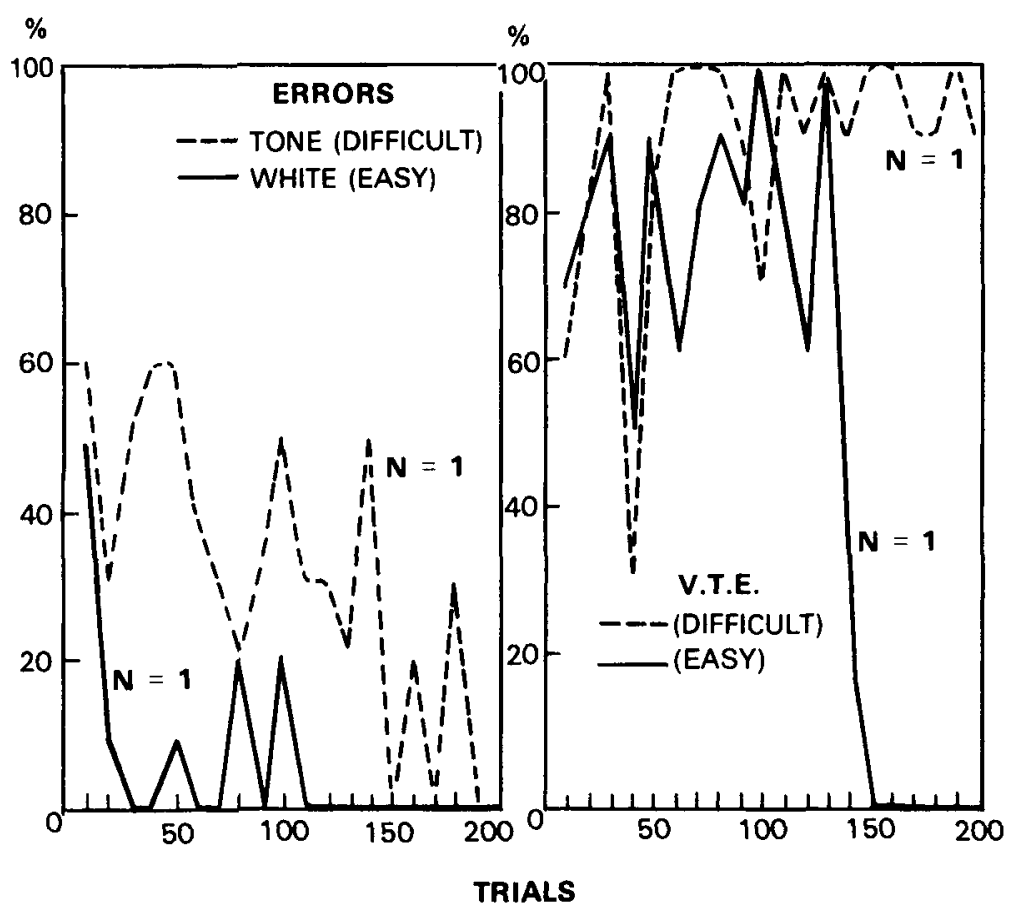

Figure 19.

First, let me show you some individual rat curves obtained by Dr. Evelyn Gentry (94) in Muenzinger's laboratory. The one rat had a difficult discrimination-namely, to go left when a tone is sounded; the other had an easy discrimination-to go towards the white in a whiteblack discrimination box (Figure 19).

At the left are the error curves and at the right the VTE curves. Whenever the rat looked one or more times before making his overt choice in a given trial that trial was recorded as having involved a VTE. The points on the curves are averages for ten trials. The solid curves are for the easy discrimination and the dash curves are for the difficult discrimination. As you see, there tended to be more VTE and the latter persisted longer for the difficult discrimination than for the easy one.

Next, let me present some recent data on VTE obtained by Mr. M. F. Friedman at California on the effect of moderate amounts of cortical lesion $^{15}$ (see Figure 20). The problem was learning to turn left on a simple elevated $T$ where one arm led to food and the other did not. The dash curves are for the brain lesion group and the solid curves are for the control group. Each point is an average of 4 trials. The normal animals exhibited more VTE and learned faster than did those with cerebral insults.

15. The histology necessary for determining the actual amounts of these lesions has not yet been done. 


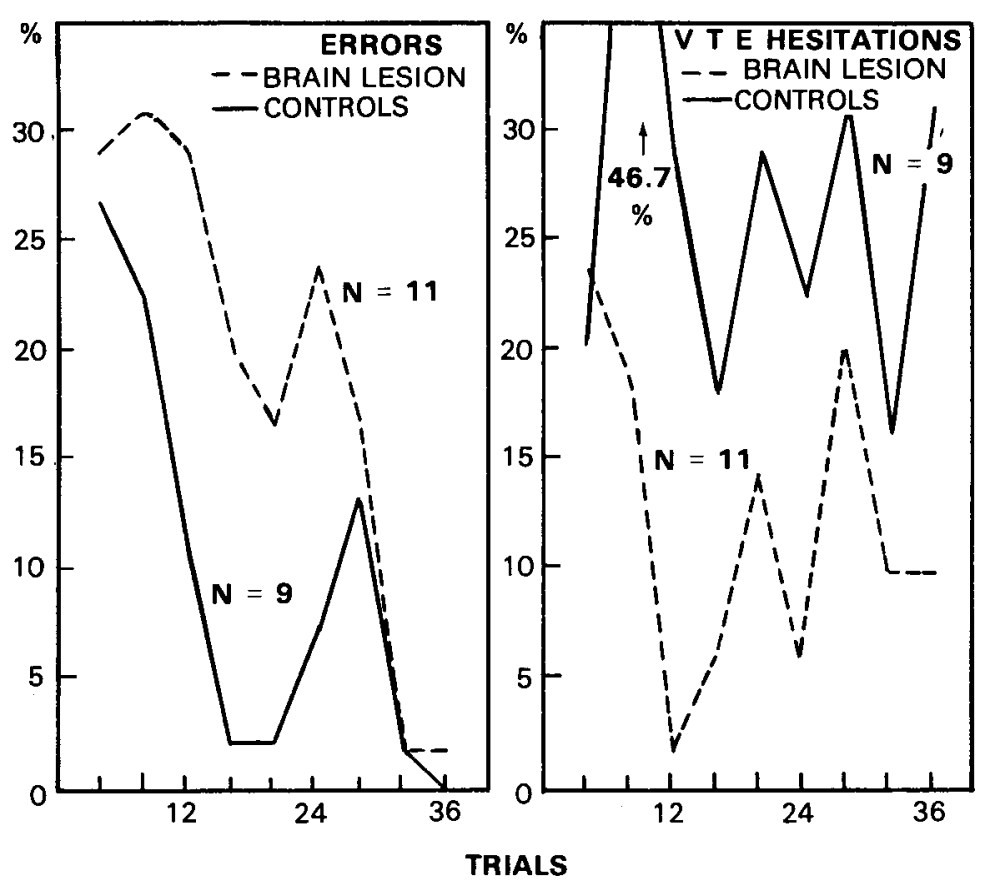

Figure 20.

Next, I present some curves obtained by Honzik with an elevated discrimination set-up. The animal had to discriminate between a black and a white face-on door. There was a partition projecting out between the doors. White was the positive stimulus. One group ran over a continuous platform and could run back around the projecting partition if they chose the wrong door first. The other group had to jump a gap of $8 \frac{1}{2}$ inches to a 4 -inch ledge just in front of the doors. If this jump group chose incorrectly, they had to jump back again to the starting platform and then make a second jump to the correct door (Figure 21). The solid curves are for the jump group and the dash curves for the non-jump group. Each point represents an average of 10 trials. The jumpers made more VTE's and learned faster.

Finally, let me present a set of curves also obtained by Honzik, in a similar set-up, but for two different jump-groups (Figure 22). The conditions for the one-jump group were those just described. We may call them here the near-jump group. For the others, which we may call the far-jump group, the farther side of the gap was 15 inches from the tobe-discriminated doors and the taking off platform $23 \frac{1}{2}$ inches from these doors. Solid curves are for the near jumpers, dash curves for the farjumpers. Each point represents an average of 10 trials.

The near-jump group learned faster and exhibited more VTE than did the far-jump group. It is to be noted that the far-jump group probably could not see the differences between the two doors at the place 


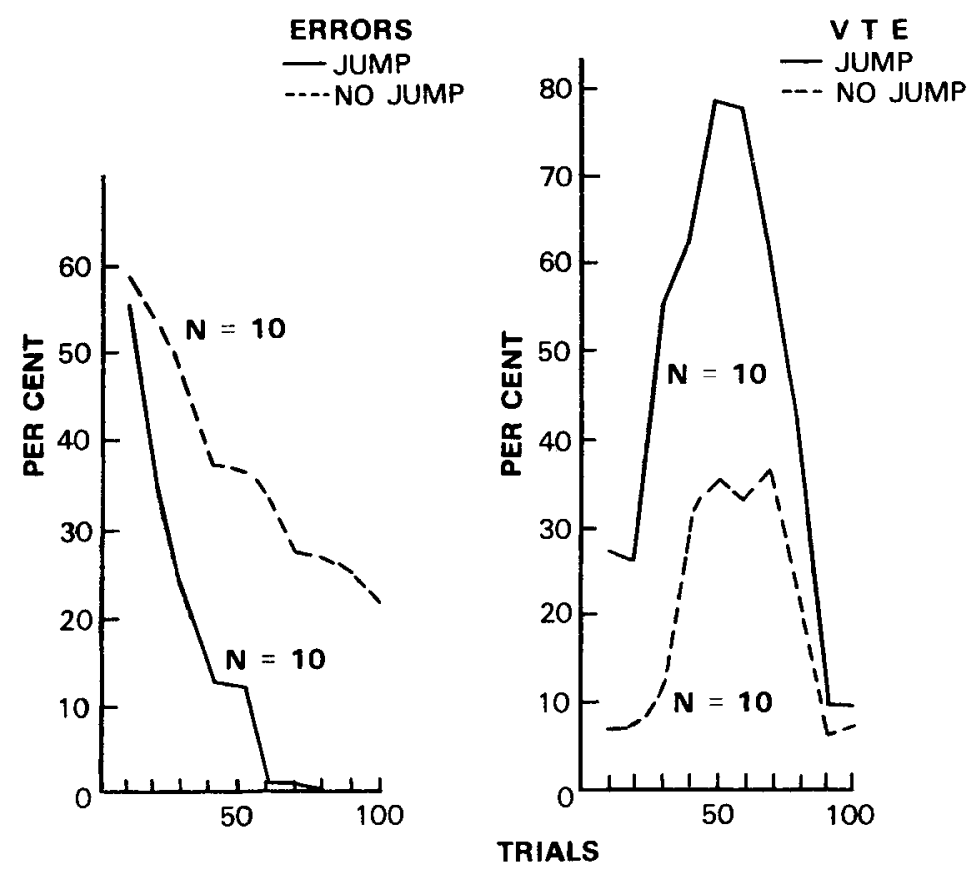

Figure 21.

of "taking off" very well. Hence their poor error score. Further, because they could not see very well, it did them little good to "go in for" "looking before they leapt." And, in fact, the VTE's for this far-jump group were decidedly less than for the near-jump group.

Let me briefly summarize: (1) For a difficult discrimination such as learning to turn left when a tone is sounded there was slower learning but more VTE than for an easy, white-black discrimination; (2) on a simple $T$, normal rats showed faster learning and exhibited more VTE than did brain lesion rats; (3) with a near-jump, jump rats learned faster and showed more VTE than did non-jump rats; (4) near-jump rats learned faster and exhibited more VTE than did far-jump rats.

What, now, is to be our theoretical envisagement? Obviously, the question divides into two: (1) What effect do VTE's, when evoked, have upon learning; (2) what are the conditions of learning which favor the evoking of such $V T E$ 's?

In answer to the first question I shall postulate that VTE's always aid the learning which they accompany. In the sole case, that of the difficult discrimination, where the poorer learning was accompanied by more $V T E$ 's I believe that this learning was nonetheless faster than it would have been if it had not been for these greater VTE's. And in all the other three experiments the greater VTE's did accompany the faster learning.

Turn now, to the second question. What are the learning conditions which tend to evoke VTE's? Here I believe we are not yet ready for any general answer. I shall therefore merely re-enumerate for your benefit the 


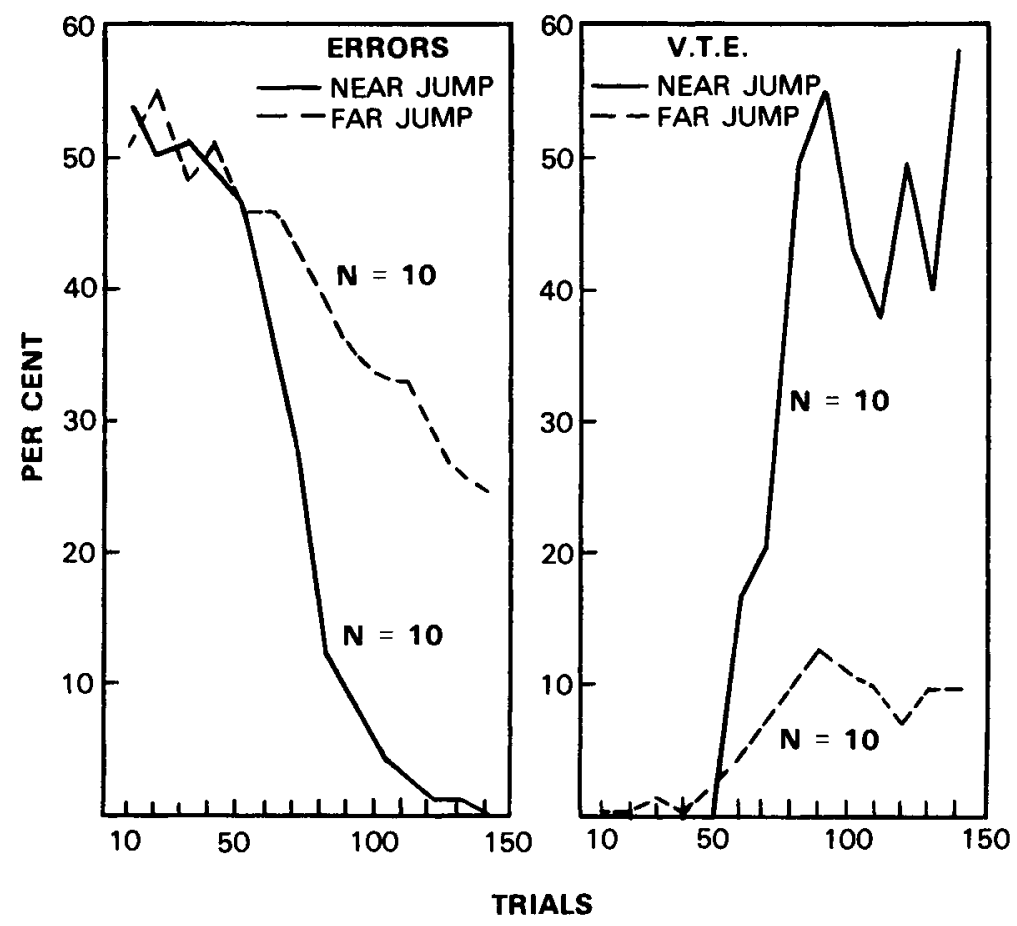

Figure 22.

conditions of the four experiments. The conditions favorable to VTE's in these experiments were: (1) a difficult discrimination; (2) a normal brain; (3) a gap to be jumped which induced caution; and (4) a nearness of the jumping platform such that the extra caution exposed the animal longer to the critical stimuli.

Finally, let me by another figure suggest how I would propose to fit this catalyzing VTE behavior into my general causal diagram (Figure 23). You will note that I have shown the VTE behavior-symbolized as $B_{V T E}$ as an auxiliary result of the "intervening variables." These latter are to be conceived as tending to produce their usual "achievement behavior" $B_{L} /\left(B_{L}+B_{R}\right)$. But, in addition, they produce more or less $B_{V T E}$, and the further catalyzing effect of such $B_{V T E}$ is, I have assumed, in some way to enhance the values of one or more of the independent variables themselves-in this case especially of $S$ and of $\Sigma(O B O)$-and thus to help induce new values of certain of the intervening variables and a new final value of the achievement behavior. That is to say, as shown in the figure, the achievement behavior takes some new value $B_{L}{ }^{\prime} l\left(B_{L}{ }^{\prime}+B_{R}{ }^{\prime}\right)$.

Turn now briefly to the case of the disruption behavior which occurs when an expected goal is not obtained. I have as yet no curves or detailed data concerning either the causes or the results of such disruption behaviors. I believe, however, that they also are to be conceived as auxiliary, catalyzing sorts of affair which react back upon the independ- 


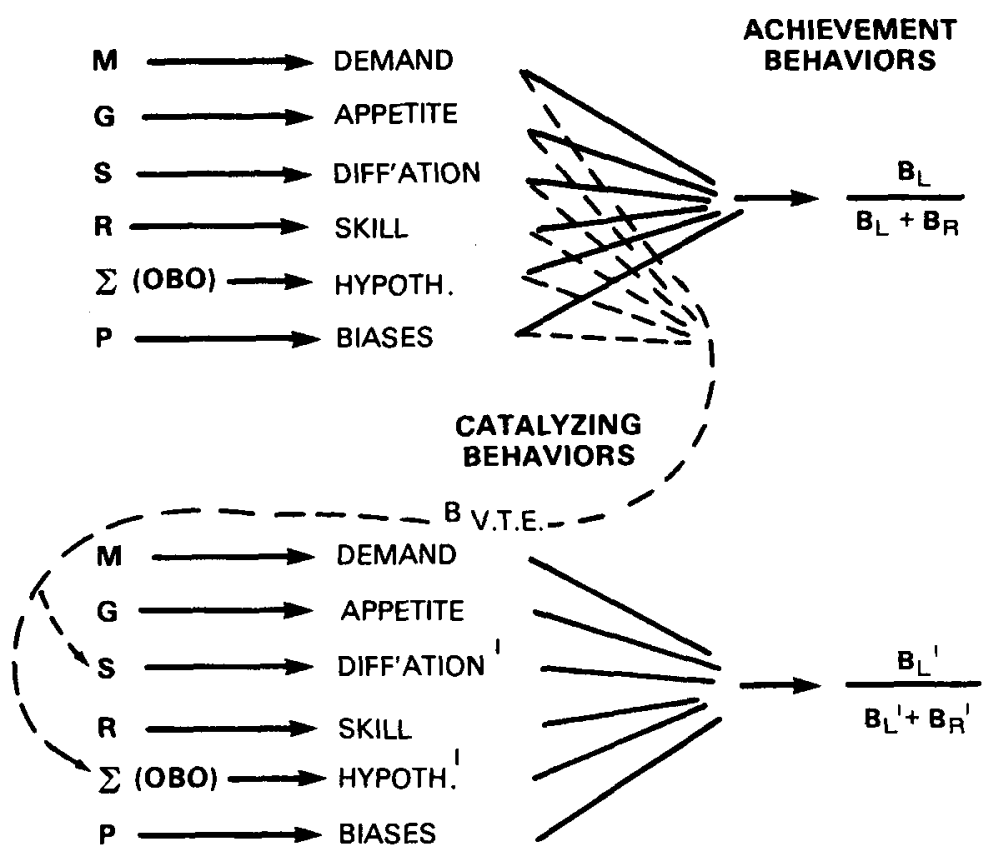

Figure 23.

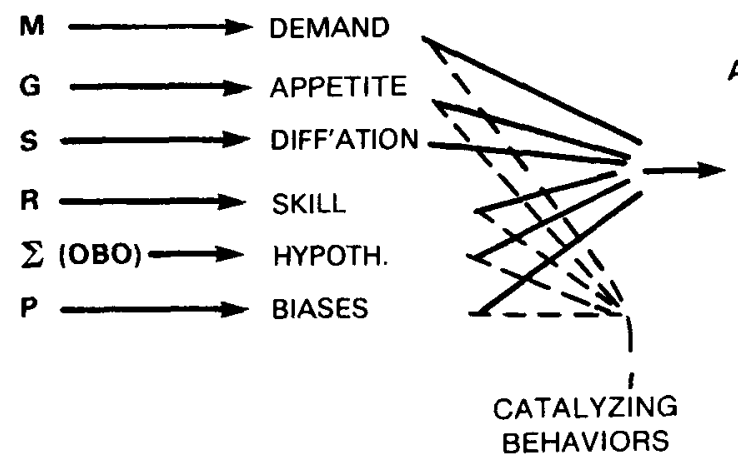

ACHIEVEMENT BEHAVIORS
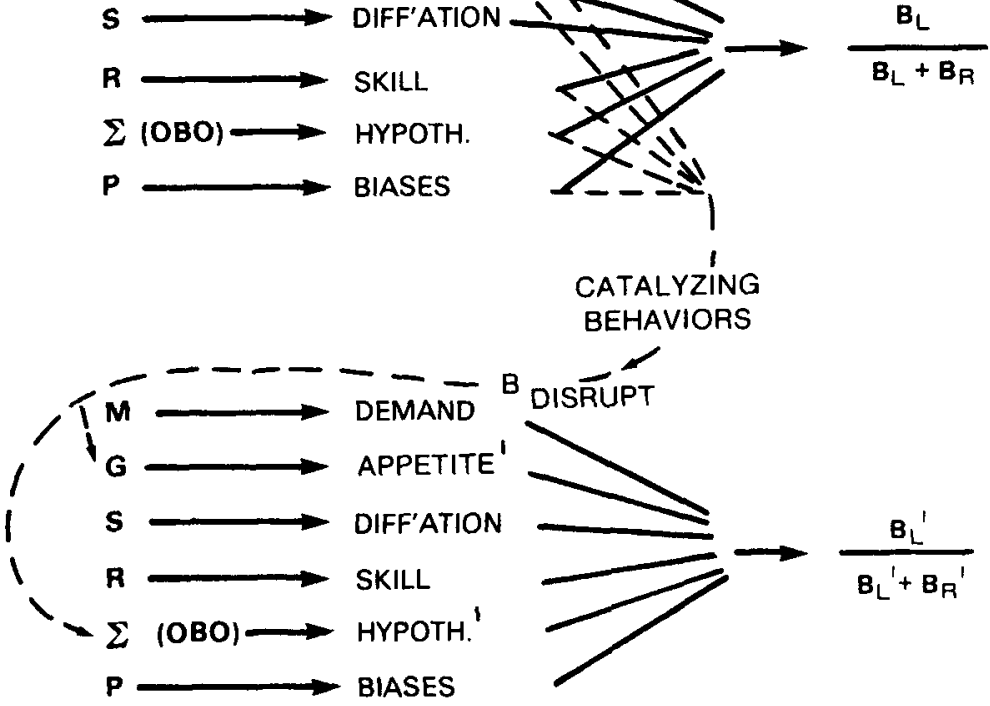

Figure 24. 
ent variables and make the final values of the resultant behavior-ratios different from what the latter originally would have been.

The rat's disrupted behavior is a surprised sort of hunting about and exploring. And it is my contention as shown in Figure 24 that this surprised hunting and exploring brings about new values of the independent variables-especially of $G$ and $\Sigma(O B O)$, - and thus causes a different outcome in the final behavior-ratio. The disrupted behavior enhances a new negative aspect in what was originally a positive goal. In short, I am assuming that because of this disrupted searching the rats are better in the next trials about not continuing to go to that side where the goal has been blocked than they would have been if this, their disrupted searching, had not appeared.

Let me close, now, with a final confession of faith. I believe that everything important in psychology (except perhaps such matters as the building up of a super-ego, that is everything save such matters as involve society and words) can be investigated in essence through the continued experimental and theoretical analysis of the determiners of rat behavior at a choice-point in a maze. Herein I believe I agree with Professor Hull and also with Professor Thorndike.

So in closing let me borrow a verse written by Alexander Meiklejohn in a copy of his book as he gave it me. He wrote, and I would now repeat:

\author{
To my ratiocinations \\ I hope you will be kind \\ As you follow up the wanderings \\ Of my amazed mind.
}

\title{
REFERENCES
}

1. Anderson, J. E., \& Smith, A. H. The effect of quantitative and qualitative stunting upon maze learning in the white rat, J. Comp. Psychol., 1926, 6, 337-361.

2. Adams, D. K. A restatement of the problem of learning, Brit. J. Psychol., 1931, 22, $150-178$.

3. Ballachey, E. L., \& Buel, J. Centrifugal swing as a determinant of choice-point behavior in the maze running of the white rat, J. Comp. Psychol., 1934, 17, 201-223.

4. Ballachey, E. L., \& Buel, J. Food orientation as a factor determining the distribution of errors in the maze running of the rat, J. Genet. Psychol., 1934, 45, 358-370.

5. Ballachey, E. L., \& Krechevsky, I. "Specific" vs. "general" orientation factors in maze running, Univ. Calif. Publ. Psychol., 1932, 6, 83-97.

6. Bayroff, A. G. Direction orientation and the forward-going tendency in white rats, $J$. Comp. Psychol., 1933, 15, 211-228.

7. Bernhardt, K. S. The effect of vitamin B deficiency during nursing on subsequent learning in the rat, J. Comp. Psychol., 1934, 17, 123-148.

8. Buel, J. The linear maze. I. "Choice-point expectancy," "correctness," and the goal gradient, J. Comp. Psychol., 1934, 17, 185 199.

9. Buel, J. Differential errors in animal mazes, Psychol. Bull., 1935, 32, 67-99.

10. Buel, J., \& Ballachey, E. L. Choice-point expectancy in the maze running of the rat, $J$. Genet. Psychol., 1934, 45, 145-168. 
11. Buel, J., \& Ballachey, E. L. Limiting factors in the effect of the reward upon the distribution of errors in mazes, Psychol. Rev., 1935, 42, 28-42.

12. Brown, W., Facing the facts, Univ. South. Calif. Proc. 25th Anniv. Inauguration Grad. Studies, Los Angeles, 1936, 116-121.

13. Bruce, R. H. A further study of the effect of variation of reward and drive upon the maze performance of rats, J. Comp. Psychol., 1935, 20, 157-182.

14. Brunswik, E. Reaction of rats to probability and danger situations (in preparation).

15. Bunch, M. E., \& Rogers, M. The relationship between transfer and the length of the interval separating the mastery of the two problems, J. Comp. Psychol., 1936, 21, 3751.

16. Carr, H. A. Psychology, a study of mental activity, New York: Longmans, Green and Co., 1925.

17. Carr, H. A. Maze studies with the white rat. I. Normal animals, J. Anim. Behav., $1917,7,259-275$.

18. Carr, H. A. Maze studies with the white rat, II. Blind animals, J. Anim. Behav., 1917, 7, 276-294.

19. Carr, H. A. Maze studies with the white rat. III. Anosmic animals, J. Anim. Behav., 1917, 7, 295-306.

20. Casper, B. The normal sensory control of the perfected double-alternation spatialmaze habit of the albino rat, J. Genet. Psychol., 1933, 43, 239-292.

21. Culler, E., Finch, F., Girden, E., \& Brogden, W. Measurements of acuity by the conditioned-response technique, J. Gen. Psychol., 1935, 12, 223-227.

22. Dashiell, J. F. Direction orientation in maze running by the white rat, Comp. Psychol. Monog., 1930, 7, No. 72.

23. Dashiell, J. F., \& Bayroff, A. G. A forward-going tendency in maze running, J. Comp. Psychol., 1931, 12, 77-94.

24. Dennis, W. The sensory control of the white rat in the maze habit, J. Genet. Psychol., $1929,36,59-90$.

25. Elliott, M. H. The effect of change of reward on the maze performance of rats, Univ. Calif. Publ. Psychol., 1928, 4, 19-30.

26. Elliott, M. H. The effect of appropriateness of reward and of complex incentives on maze performance, Univ. Calif. Publ. Psychol., 1929, 4, 91-98.

27. Elliott, M. H. Some determining factors in maze performance, Amer. J. Psychol, $1930,42,315-317$.

28. Ellis, W. D., \& Hamilton, J. A. Behavior constancy, J. Gen. Psychol., 1933, 8, 421-429.

29. Gellermann, L. W. Form discrimination in chimpanzees and two-year-old children: I. Discrimination of form per se. II. Form versus background, J. Genet. Psychol., $1933,42,3-50$.

30. Gengerelli, J. A. The principle of maxima and minima in animal learning, J. Comp. Psychol., 1930, 11, 193-236.

31. Gilhousen, H. C. An investigation of "insight" in rats, Science, 1931, 73, 711.

32. Gilhousen, H. C. Fixation of excess distance patterns in the white rat, J. Comp. Psychol., 1932, 16, 1-24.

33. Guthrie, E. R. The psychology of learning, New York: Harper and Brothers, 1935.

34. Hall, C. S. Emotional behavior in the rat. I. Defecation and urination as measures of individual differences in emotionality, J. Comp. Psychol., 1934, 18, 385-403.

35. Hall, C. S. Emotional behavior in the rat. II. The relationship between need and emotionality, J. Comp. Psychol., 1936, 22, 61-68.

36. Hall, C. S. Emotional behavior in the rat. III. The relationship between emotionality and ambulatory activity, J. Comp. Psychol., 1936, 22, 345-352.

37. Hall, C. S., \& Ballachey, E. L. A study of the rat's behavior in a field: A contribution to method in comparative psychology, Univ. Calif. Publ. Psychol, , 1932, 6, 1-12.

38. Hamilton, J. A., \& Ellis, W. D. Behavior constancy in rats, J. Genet. Psychol., 1932, 41, 120-139.

39. Hamilton, J. A., \& Ellis, W. D. Persistence and behavior constancy, I. Genet. Psychol., 1932, 41, 140-153. 
40. Heron, W. T. Complex learning processes, in "Comparative Psychology," F. A. Moss (Ed.), New York: Prentice-Hall, Inc., 1934, pp. 335-366.

41. Heron, W. T. The inheritance of maze learning ability in rats, J. Comp. Psychol., 1935, 19, 77-90.

42. Hilgard, E. R. The nature of the conditioned response: I. The case for and against stimulus-substitution, Psychol. Rev., 1936, 43, 366-385.

43. Hilgard, E. R. The nature of the conditioned response: II. Alternatives to stimulus substitution, Psychol. Rev., 1936, 43, 547-564.

44. Hilgard, E. R. The relationship between the conditioned response and conventional learning experiments, Psychol. Bull., 1937, 34, 61-102.

45. Holt, E. B. Animal drive and the learning process, New York: Henry Holt and Company, 1931, Vol. I., p. $151 \mathrm{f}$.

46. Honzik, C. H. The sensory basis of maze learning in rats, Comp. Psychol. Monog., 1936, 13, Serial No. 64.

47. Honzik, C. H., \& Tolman, E. C. The perception of spatial relations by the rat: a type of response not easily explained by conditioning, J. Comp. Psychol., 1936, 22, 287318.

48. Hull, C. L. The concept of the habit-family hierarchy and maze learning. Part I., Psychol. Rev., 1934, 41, 33-54.

49. Hull, C. L. Mind, mechanism, and adaptive behavior, Psychol. Rev., 1937, 44, 1-32.

50. Hunter, W. S. The sensory control of the maze habit in the white rat, J. Genet. Psychol., 1929, 36, 505-537.

51. Hunter, W. S. A further consideration of the sensory control of the maze habit in the white rat, J. Genet. Psychol., 1930, 38, 3-19.

52. Kelley, T. L. Crossroads in the mind of man, Stanford University: Stanford University Press, 1928.

53. Klüver, H. Behavior mechanisms in monkeys, Chicago: University of Chicago Press, 1933.

54. Koch, H. C. The influence of mechanical guidance upon maze learning, Psychol. Monog., 1923, 32, No. 147.

55. Köhler, W. Gestalt psychology, New York: Horace Liveright, 1929.

56. Koffka, K. Principles of gestalt psychology, New York: Harcourt, Brace and Company, 1935.

57. Krechevsky, I. "Hypotheses" in rats, Psychol. Rev., 1932, 39, 516-532.

58. Krechevsky, I. Brain mechanisms and brightness discrimination learning, J. Comp. Psychol., 1936, 21, 405-446.

59. Krechevsky, I. Brain mechanisms and variability. I. Variability within a means-endreadiness, J. Comp. Psychol., 1937, 23, 121-138.

60. Krechevsky, I. Brain mechanisms and variability. II. Variability where no learning is involved, J. Comp. Psychol., 1937, 23, 139-163.

61. Krechevsky, I. Brain mechanisms and variability. III. Limitations of the effect of cortical injury upon variability, J. Comp. Psychol., 1937, 23, 351-364.

62. Krechevsky, I., \& Honzik, C. H. Fixation in the rat, Univ. Calif. Publ. Psychol., 1932, 6, 13-26.

63. Lashley, K. S. Learning: I. Nervous-mechanisms of learning, in "The Foundations of Experimental Psychology,'Worcester, Mass.: Clark University Press, 1929, pp. 524563.

64. Leeper, R. The rôle of motivation in learning: A study of the phenomenon of differential motivational control of the utilization of habits, J. Genet. Psychol., 1935, $46,3-40$.

65. Lewin, K. A dynamic theory of personality, New York: McGraw-Hill Book Company, Inc., 1935.

66. Lewin, K. Principles of topological psychology, New York: McGraw-Hill Book Company, Inc., 1936.

67. Liddell, H. S. The conditioned reflex, in "Comparative Psychology," F. A. Moss (Ed.), New York: Prentice-Hall, Inc., 1934, pp. 247-296. 
68. Lindley, S. B. The maze-learning ability of anosmic and blind anosmic rats, J. Genet. Psychol., 1930, 37, 245-267.

69. Lorge, I. Irrelevant rewards in animal learning, J. Comp. Psychol., 1936, 21, 105-128.

70. Loucks, R. B. An appraisal of Pavlov's systematization of behavior from the experimental standpoint, J. Comp. Psychol., 1933, 15, 1-45.

71. Loucks, R. B. Reflexology and the psychobiological approach, Psychol. Rev., 1937, 44, 320-338.

72. Ludgate, K. E. The effect of manual guidance upon maze learning, Psychol. Monog., 1923, 33, No. 148.

73. Macfarlane, D. A. The rôle of kinesthesis in maze learning, Univ. Calif. Publ. Psychol., 1930, 4, 277-305.

74. Maier, N. R. F. Reasoning in white rats, Comp. Psychol. Monog., 1929, 6, 3.

75. Maier, N. R. F. In defense of reasoning in rats, J. Comp. Psychol., 1935, 19, 197-206.

76. Maier, N. R. F. Age and intelligence in rats, J. Comp. Psychol., 1932, 13, 1-16.

77. Maier, N. R. F. The effect of cerebral destruction on reasoning and learning in rats, $J$. Comp. Neur., 1932, 54, 45-75.

78. Maurer, $S$. The effect of partial depletion of vitamin $B\left(B^{1}\right)$ upon performance in rats. III., J. Comp. Psychol., 1935, 20, 309-318.

79. Maurer, $S$. The effect of early depletion of vitamin $B_{2}$ upon the performance in rats. IV., J. Comp. Psychol., 1935, 20, 385-388.

80. Maurer, S. The effect of acute vitamin A depletion upon performance in rats. V., $J$. Comp. Psychol., 1935, 20, 389-392.

81. Maurer, S. The effect of a diet of pasteurized milk upon performance in rats. VI., $J$. Comp. Psychol., 1935, 20, 393-396.

82. Maurer, S., \& Tsai, L. S. Vitamin B deficiency and learning ability, J. Comp. Psychol., $1930,11,51-62$.

83. Maurer, S., \& Tsai, L. S. The effect of partial depletion of vitamin B complex upon learning ability in rats, $J$. Nutrition, 1931, 4, No. 4.

84. McCulloch, T. L. Performance preferentials of the white rat in force-resisting and spatial dimension, J. Comp. Psychol., 1934, 18, 85-111.

85. Miller, N. E., \& Miles, W. R. Effect of caffeine on the running speed of hungry, satiated, and frustrated rats, J. Comp. Psychol., 1935, 20, 397-412.

86. Moss, F. A. The effect of drugs and internal secretions on animal behavior, in "Comparative Psychology," F. A. Moss (Ed.), New York: Prentice-Hall, Inc., 1934, pp. 113-148.

87. Muenzinger, K. F. Motivation in learning. I. Electric shock for correct response in the visual discrimination habit, J. Comp. Psychol., 1934, 17, 267-277.

88. Muenzinger, K. F. Motivation in learning. II. The function of electric shock for right and wrong responses in human subjects, J. Exper. Psychol., 1934, 17, 439-448.

89. Muenzinger, K. F., \& Newcomb, H. Motivation in learning. III. A bell signal compared with electric shock for right and wrong responses in the visual discrimination habit, J. Comp. Psychol, 1935, 20, 85-93.

90. Muenzinger, K. F., \& Wood, A. Motivation in learning. IV. The function of punishment as determined by its temporal relation to the the act of choice in the visual discrimination habit, J. Comp. Psychol., 1935, 20, 95-106.

91. Muenzinger, K. F., \& Newcomb, H. Motivation in learning. V. The relative effectiveness of jumping a gap and crossing an electric grid in a visual discrimination habit, J. Comp. Psychol., 1936, 21, 95-104.

92. Muenzinger, K. F., \& Fletcher, F. M. Motivation in learning. VI. Escape from electric shock compared with hunger-food tension in the visual discrimination habit, $J$. Comp. Psychol., 1936, 22, 79-91.

93. Muenzinger, K. F., \& Fletcher, F. M. Motivation in learning. VII. The effect of an enforced delay at the point of choice in the visual discrimination habit, J. Comp. Psychol., 1937, 23, 383-392.

94. Muenzinger, K. F., \& Gentry, E. Tone discrimination in white rats, J. Comp. Psychol., 1931, 12, 195-206. 
95. Muenzinger, K. F., \& Dove, C. C. Serial Learning: I. Gradients of uniformity and variability produced by success and failure of single responses, J. Gen. Psychol., $1937,16,403-414$.

96. Muenzinger, K. F., Poe, E., \& Poe, C. F. The effect of vitamin deficiency upon the acquisition and retention of the maze habit in the white rat. II. Vitamin $B_{2}(G), J$. Comp. Psychol., 1937, 23, 59-66.

97. Munn, N. L. An introduction to animal psychology, the behavior of the rat, New York: Houghton Mifflin Company, 1933.

98. Poe, E., Poe, C. F., \& Muenzinger, K. F. The effect of vitamin deficiency upon the acquisition and retention of the maze habit in the white rat. I. The vitamin $B$ complex, J. Comp. Psychol., 1936, 22, 69-77.

99. Poe, E., Poe, C. F., \& Muenzinger, K. F. The effect of vitamin deficiency upon the acquisition and retention of the maze habit in the white rat. III. Vitamin $\mathrm{B}^{1}, I$. Comp. Psychol., 1937, 23, 67-76.

100. Ruch, F. L. Goal direction orientation, generalized turning habit and goal gradient as factors in maze learning in the rat, J. Comp. Psychol., 1934, 17, 225-232.

101. Ruch, F. L. Experimental studies of the factors influencing the difficulty of blind alleys in linear mazes. I. Experiments with the maze patterns RLRLLRLRRLRL and LRLRRLRLLRLR, J. Comp. Psychol., 1935, 20, 21-34.

102. Ruch, F. L. Experimental studies of the factors influencing the difficulty of blind alleys in linear mazes. II. Generalized-turning habits, J. Comp. Psychol., 1935, 20, 35-52.

103. Ruch, F. L. Experimental studies of the factors influencing the difficulty of blind alleys in linear mazes. III. Is there an anticipatory tendency in maze learning?, J. Comp. Psychol., 1935, 20, 113-124.

104. Rundquist, E. E. Inheritance of spontaneous activity in rats, J. Comp. Psychol., 1933, $16,415-438$.

105. Schlosberg, H. Conditioned responses in the white rat, J. Genet. Psychol., 1934, 45, 303-335.

106. Schlosberg, $H$. The relationship between success and the laws of conditioning, Psychol. Rev., 1937, 44, 379-394.

107. Schneirla, T. C. Learning and orientation in ants, Comp. Psychol. Monog., 1929, 6, No. 30, pp. 143.

108. Skinner, B. F. Two types of conditioned reflex and a pseudo type, J. Gen. Psychol., $1935,12,66-77$.

109. Spearman, C. The nature of "intelligence" and the principles of cognition, London: Macmillan and Co., 1927.

110. Spence, K. W. The order of eliminating blinds in maze learning by the rat, J. Comp. Psychol., 1932, 14, 9-27.

111. Spence, K. W., \& Shipley, W. C. The factors determining the difficulty of blind alleys in maze learning by the white rat. J. Comp. Psychol., 1934, 17, 423-436.

112. Spragg, S. D. S. Anticipation as a factor in maze errors, J. Comp. Psychol., 1933, 15, 319-329.

113. Spragg, S. D. S. Anticipatory responses in the maze, J. Comp. Psychol., 1934, 18, 5173.

114. Stone, C. P. The age factor in animal learning: I. Rats in the problem box and the maze. II. Rats on a multiple light discrimination box and a difficult maze, Genet. Psychol. Monog., 1925, 5, 1-130; 6, 125-202.

115. Stone, C. P. Motivation: drives and incentives, in "Comparative Psychology," F. A. Moss (Ed.), New York: Prentice-Hall, Inc., 1934, pp. 73-112.

116. Thorndike, E. L. Educational psychology, Vol. III.; mental work and fatigue; Individual differences and their causes, New York: Teachers College, Columbia University, 1923.

117. Thomdike, E. L. The measurement of intelligence, New York: Teachers College, Columbia University, 1927.

118. Thorndike, E. L. The fundamentals of learning, New York: Teachers College, Columbia University, 1932. 
119. Thorndike, E. L. Wants, interest and attitudes, New York: The Century Co., 1935.

120. Thurstone, L. L. The vectors of mind, Chicago: University of Chicago Press, 1935.

121. Tolman, E. C. A behaviorist's definition of consciousness, Psychol. Rev., 1927, 34, 433-439.

122. Tolman, E. C. Purposive behavior in animals and men, New York: The Century Co., 1932, Ch. 13.

123. Tolman, E. C. The law of effect: a reply to Dr. Goodenough, J. Exper. Psychol., 1933, $16,459-462$.

124. Tolman, E. C. Psychology vs. immediate experience, Philos. Science, 1935, 2, 356-380.

125. Tolman, E. C. Distance-preferentials. A new apparatus and some results, Psychol. Bull., 1936, 33, 727.

126. Tolman, E. C. Operational behaviorism and current trends in psychology, Proc. 25th Anniv. Celebration Inaug. Grad Stud., Los Angeles: The University of Southern California, 1936, pp. 89-103.

127. Tolman, E. C., Hall, C. S., \& Bretnall, E. P. A disproof of the law of effect and a substitution of the laws of emphasis, motivation and disruption, J. Exper. Psychol., $1932,15,601-614$.

128. Tolman, E. C., \& Honzik, C. H. "Insight" in rats, Univ. Calif. Publ. Psychol., 1930, 4, 215-232.

129. Tryon, R. D. The genetics of learning ability in rats: preliminary report, Univ. Calif. Publ. Psychol., 1929, 4, 71-89.

130. Tryon, R. C. Individual differences, in "Comparative Psychology," F. A. Moss (Ed.), New York: Prentice-Hall, Inc., 1934, pp. 409-448.

131. Tryon, R. C. A theory of psychological components-an alternative to "mathematical factors," Psychol. Rev., 1935, 42, 425-454.

132. Tsai, L. S. Gradual vs. abrupt withdrawal of guidance in maze learning, J. Comp. Psychol., 1930, 10, 325-332.

133. Tsai, L. S. The laws of minimum effort and maximum satisfaction in animal behavior, Monog. Nat. Instit. Psychol., 1932, No. 1, pp. 49, (seen in Psychol. Abst., 1936, 6, No. 4329).

134. Vaughn, C. L. Factors in rat learning-an analysis of the intercorrelations between 34 variables, Comp. Psychol. Monog., 1937, 14, Serial No. 69.

135. Wang, T. L. The influence of tuition in the acquisition of skill, Psychol. Monog., 1925, 33, No. 154.

136. Warden, C. J. Animal motivation, Experimental studies on the Albino Rat. New York: Columbia University Press, 1931.

137. Waters, R. H. The influence of large amounts of manual guidance upon human maze learning, J. Gen. Psychol., 1930, 4, 213-228.

138. Waters, R. H. Equivalence of response in learning, Psychol. Bull., 1936, 33, 798-799.

139. Waters, R. H. The wall-seeking tendency and maze learning in the white rat, $/$. Psychol., 1937, 4, 23-26.

140. Waters, R. H. The principle of least effort in learning. J. Gen. Psychol., 1937, 16, 3-20.

141. Watson, J. B. Kinaesthetic and organic sensations: Their rôle in the reactions of the white rat, Psychol. Rev. Monog., 1917, 8, 2.

142. Webb, L. W. Transfer of training and retroaction, Psychol. Rev. Monog., 1917, 24, No. 3.

143. Wheeler, R. H. The science of psychology, New York: Thomas Y. Crowell Company, 1929.

144. Williams, G. W., \& $O^{\prime}$ Brien, C. The effect of sodium phenobarbital on the learning behavior of white rats, J. Comp. Psychol., 1937, 23, 457-474.

145. Wilson, W. R. Principles of selection in "trial and error" learning, Psychol Rev., 1924, $31,150-160$.

146. Witkin, H. A., \& Schneirla, T. C. Initial maze behavior as a function of maze design, J. Comp. Psychol., 1937, 23, 275-304.

147. Wolfle, D. L. The effects of continuous interchange of alley sections on the maze behavior of rats, J. Comp. Psychol., 1935, 19, 91-106. 
148. Wright, H. F. The influence of barriers upon strength of motivation, Contrib. Psychol. Theory, Vol. I, No. 3, Duke Univ. Press, 1937.

149. Yoshioka, J. G. Direction as a factor in maze solution in rats, J. Genet. Psychol., 1930, $38,307-320$.

150. Yoshioka, J. G. A study of orientation in a maze, J. Genet. Psychol., 1933, 42, 167183.

151. Young, P. T. Preferential discrimination of the white rat for different kinds of grain, Amer. J. Psychol., 1928, 40, 372-400.

152. Young, P. T. Relative food preferences of the white rat, J. Comp. Psychol., 1932, 14, 297-319.

153. Young, P. T. Relative food preferences of the white rat. II., J. Comp. Psychol., 1933, $15,149-166$. 